\title{
El rol de los servicios urbanos en la legalización predial y la generación de calidad urbana y valor del suelo. Aplicación al caso de Cúcuta (Colombia)
}

\author{
The role of urban services in land legalization and \\ the generation of urban quality and land value. \\ Application to the case of Cucuta (Colombia)
}

\author{
Carlos Felipe Urazán Bonells* y Francesc Magrinyà Torner*
}

Fecha de recepción: 15-04-2014 - Fecha de aceptación: 15-03-2015

Hábitat y Sociedad (ISSN 2173-125X), n. ${ }^{\circ}$, noviembre de 2015, pp. 113-145.

\begin{abstract}
Summary
The growing phenomenon of urbanization in developing countries has led to a large number of settlements characterized by a deficient habitat (slums), lacking security of tenure and an adequate provision of urban services that affect the quality of the lives of its citizens. Over time, these settlements are improving their standards of quality in the provision of public services and their security of tenure. The interrelationship between security of tenure, improved urban services and housing improvement provides the key to evaluating the actions that improve the quality of life of its inhabitants. The proposed approach involves the establishment of a methodology for reading the evolution of the forms of urban growth in terms of incremental levels of security of tenure $(\mathrm{P})$, urban services $(\mathrm{U})$, and building $(\mathrm{E})$. In order to develop the analysis, an urban periphery index has been developed, based on the forms of evolutionary growth, improved services and security tenure, as well as on accessibility (distance to the centre and slope). The analysis of the correlation between the urban periphery index and the spatial distribution of social strata and land values, in the evolution of the urbanization of the city of Cucuta (Colombia), highlights the relevance of the elements of the urban periphery index as key factors to improve the quality of life..
\end{abstract}

\section{Key words}

Habitat, Production and Social Management of the Habitat, Sustainability, Social Transformation

\begin{abstract}
Resumen
El creciente fenómeno de la urbanización que viven los países en desarrollo ha dejado como consecuencia un gran número de asentamientos con un hábitat deficitario (tugurios), caracterizado por carecer de seguridad de la tenencia y de una adecuada prestación de servicios urbanos que condicionan la calidad de vida de sus ciudadanos. Esos asentamientos van mejorando con el paso del tiempo sus niveles de calidad en la prestación de servicios y su grado de parcelación. La interrelación entre la legalización predial, la mejora de los servicios urbanos y la mejora de la vivienda es clave para evaluar las acciones que mejoran la calidad de vida de sus habitantes. El planteamiento propuesto es establecer una metodología de lectura de la evolución de las formas de crecimiento urbano según niveles incrementales de parcelación $(\mathrm{P})$, de servicios urbanos (U) y de edificación (E). Para el desarrollo del análisis se ha elaborado un índice urbano de periferia establecido a partir de las formas de crecimiento evolutivas, la mejora de los servicios y de legalización predial, así como de las condiciones de accesibilidad (distancia al centro y pendiente). El análisis de la correlación entre el índice urbano de periferia y la distribución espacial de estratos sociales y de valores del suelo en la evolución de la urbanización de la ciudad de Cúcuta (Colombia), pone en evidencia la pertinencia de los elementos que configuran el índice urbano de periferia como elementos claves de la mejora de calidad de vida.
\end{abstract}

\section{Palabras clave}

Hábitat, Producción y Gestión social del Hábitat, Sostenibilidad, Transformación social

\footnotetext{
* Ingeniero civil. Doctor en Gestión del Territorio e Infraestructura del Transporte. Profesor de la Universidad de La Salle, Bogotá, Colombia. Email: caurazan@unisalle.edu.co.

** Ingeniero de Caminos, Canales y Puertos. Doctor en Urbanismo. Profesor de la Universidad Politécnica de Cataluña, Barcelona, España. Coordinador del Grupo de Investigación EXIT (Ingeniería, Redes, Infraestructuras y Transporte). Coordinador Laboratorio IntraScapeLab (www.intrascapelab.wordpress.com). Email: francesc.magrinya@upc.edu.
} 


\section{La necesidad de establecer criterios para la reducción de la pobreza en la urbanización}

Hay multitud de estudios sobre la relación entre la ciudad formal e informal (Trivelli, 1986; Hardoy y Satterhwaite, 1987; Durand-Lasserve y Clerc, 1996), así como de análisis de las propuestas de mejoramientos de barrios (Brakarz, Greene y Rojas, 2002; Valladares, 2003; Calderon Cockburn, 2004; Salas, 2005; MacDonald, 2005; Costa y Hernandez, 2010). El proceso de urbanización ha traído consigo una gran generación de pobreza, expresada en la precariedad urbana, caracterizada por un hábitat deficitario que tiene como patrones la deficiencia en el nivel sanitario (abastecimiento de agua y saneamiento básico) y la falta de seguridad de la tenencia (MacDonald, 2004). Se establece, pues, una relación entre mayor nivel de urbanización y niveles menores de pobreza (MacDonald, 2005). En América Latina el proceso de urbanización ha estado ligado a la pobreza urbana desde mediados del siglo XX, que es cuando se aceleró la emigración campo-ciudad. Ese hecho fue abordado inicialmente con dotación de vivienda nueva, asegurando la mínima calidad de los servicios y la seguridad de la tenencia (décadas de 1960 y 1970). A partir de 1980, el problema del hábitat deficitario fue intervenido desde los asentamientos ya existentes con dotación de infraestructura y servicios (Valladares y Prates, 2003). La década de 1990 representa un umbral en que al principio el crecimiento de urbanización se acompañaba de un aumento en la pobreza ligado a una reducción de la economía. Pasado el umbral, la urbanización continuaba, pero la pobreza se reducía acompañada por una mejora económica (Rodríguez Vignoli, 2006). Se establece, pues, una relación entre mayor nivel de urbanización y niveles menores de pobreza (McDonald, 2005).

\section{Mejora de vivienda y de servicios urbanos, legalización de predios y mejora de barrios}

En las investigaciones de políticas urbanas para tejidos informales ya se plantea desde hace tiempo un planteamiento global para situar una visión de conjunto en la mejora de las condiciones de vida de sus habitantes (Trivelli, 1986). Ante la imprecisión de la caracterización del periurbano (Puebla, 2010), es necesario precisar los distintos prados de periferia. Dematteis (1996) pone en evidencia la necesidad de recoger una lectura más en red para la lectura de las periferias urbanas. Arteaga (2005), para definir periferia, nos propone los conceptos de localización topográfica y el doble fenómeno de expansión según coronas y según centros urbanos relevantes. Mansilla (2013) demanda la necesidad de establecer el concepto de periurbano a partir de las variadas formas de producción de los espacios periurbanos. Por otra parte, y tal como señala Calderón Cockburn (2004), en la ciudad informal las políticas no reconocen en la medida necesaria la interrelación entre las diversas formas de ilegalidad y su retroalimentación mutua. Recientemente, se hace insistencia en los procesos de producción del hábitat para poder tener una buena gestión de la producción social del hábitat (Pelli, 2010).

Para avanzar en este análisis nos interesaremos en las interacciones entre mejora de vivienda, mejora de servicios urbanos y legalización de 
predios para una mejor eficacia en las mejoras de barrios. Rodriguez et $a l$. (2007) ponen en valor la necesidad de inversión en infraestructura y equipamiento y servicios en las periferias. En Bogotá, especialmente en Ciudad Bolívar, se planteaba la cuestión sobre la posibilidad de ofertar servicios públicos en barrios ilegales (Decastro, 2012). Cuáles son los tiempos de cada mejora y el rol de cada uno de los factores será uno de los factores que más nos interesará en esta investigación.

\section{Metodología de análisis: las formas de crecimiento urbano-evolutivas}

Este trabajo entra claramente en esta línea, ya que es una investigación evolutiva del conjunto de una ciudad durante un siglo. Para la definición de una lectura evolutiva de la formalización proponemos un marco teórico que incluye un análisis topográfico, un análisis de los desarrollos institucionales y su influencia sobre los tejidos formales e informales y un análisis del rol de las formas de crecimiento urbano. El conjunto de estas variables nos permitirá establecer un índice urbano de periferia que correlacionaremos con el valor del suelo y el reparto de los distintos estratos sociales. Este trabajo se propone analizar la relación entre centro-periferia mediatizada por las redes de servicios urbanos y el rol de un cierto policentrismo asociado a la política pública y propone una lectura del proceso de formalización de tejidos informales según la distancia al centro urbano, el nivel de conexión a las redes y el proceso de legalización de la parcela que denominaremos índice urbano de periferia. Nuestro objetivo es, en definitiva, establecer el rol que tienen la urbanización y la parcelación en la evolución de la formalización de los tejidos urbanos, y qué implicaciones tienen estas en la generación de valor del suelo y de reparto de los distintos estratos sociales.

Para el análisis de la correlación entre parcelación, urbanización y edificación se ha tomado el esquema PUE (figura 1). En este modelo, de las distintas combinaciones de la parcelación (P) y/o la urbanización (U) y/o la edificación (E), se deriva el concepto de las Formas de Crecimiento Urbano, en el que las distintas combinaciones de sus componentes $-\mathrm{E}, \mathrm{P}+\mathrm{E}, \mathrm{U}+\mathrm{P}+\mathrm{E}, \mathrm{P}+\mathrm{U}+\mathrm{E}, \mathrm{UP}+\mathrm{E}$. PUE- se presentan en principio como la cristalización en un momento dado de unos actores y unas formas que dan lugar una estructura de crecimiento (Solà Morales, 1997).

Sobre este esquema, y en una lectura evolutiva e incremental de cada una de las variables (P, U y E), se propone una lectura más avanzada en la que cristalizan en momentos sucesivos una serie de formas de crecimiento urbano que se irían sucediendo (Magrinyà, 2005), generando así una evolución en los niveles de servicio de cada una de las variables, siguiendo la nomenclatura de Herce y Miró (2002). Este planteamiento evolucionado de las formas de crecimiento urbano queda representado en el esquema
Figura 1. Esquema de las Formas de Crecimiento Urbano. Fuente: Solà Morales, 1997

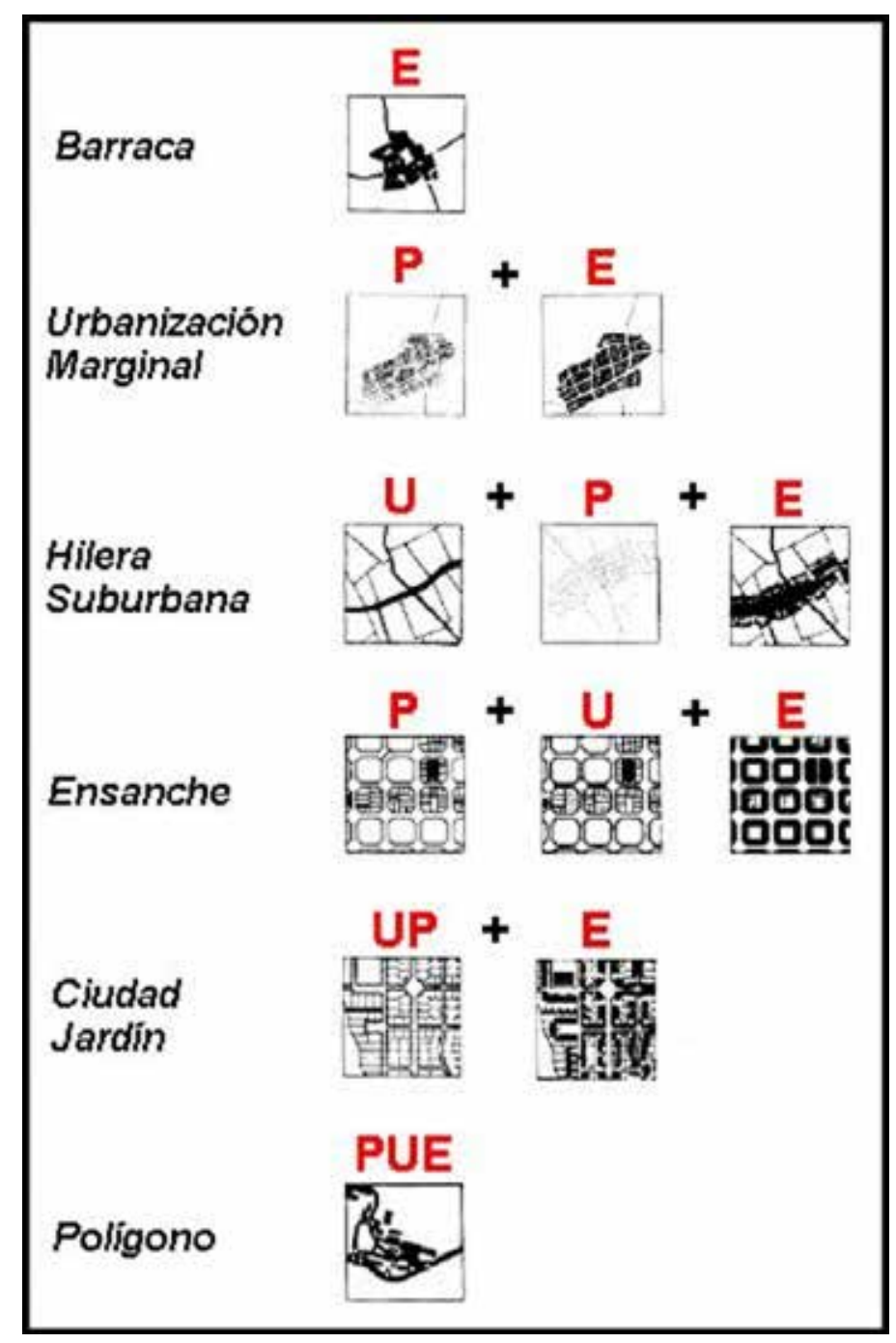


P U E (Parcelación, Urbanización, Edificación)

Evolución

espacial

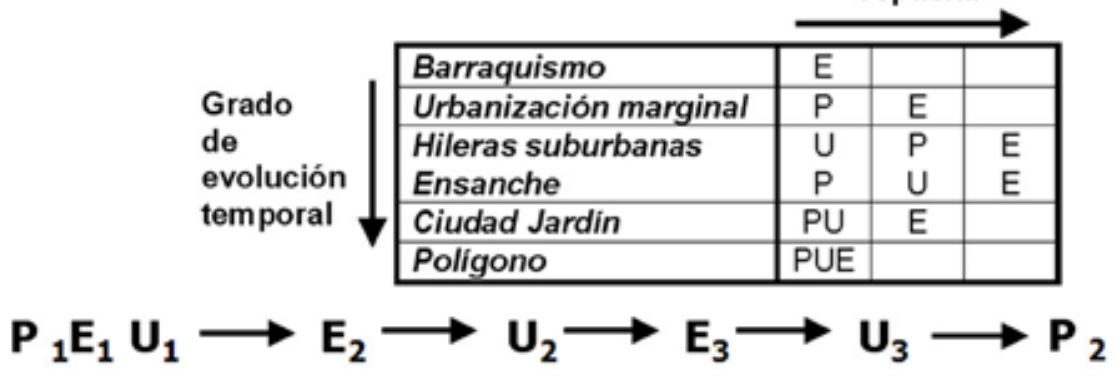

de la figura 2 y ha tenido un primer análisis de aplicación al caso de Barcelona (España) (Magrinyà, 2008) . El esquema planteado permite analizar las interacciones a lo largo del tiempo entre la parcelación, la urbanización con sus distintos servicios, y la edificación. Esa dinámica se ha tomado como herramienta de referencia en este estudio para analizar y conocer el rol que tienen los servicios urbanos en la legalización de los predios.

Figura 2. Esquema evolutivo de las Formas de Crecimiento Urbano. Fuente: Magrinyà, 2005

1 La ciudadela Atalaya corresponde al sector de la ciudad ubicado al costado occidental del denominado "cerro occidental", y la ciudadela San Luis es el sector ubicado al costado oriental del río Pamplonita.
Por otra parte, se analizará el rol de los actores y las dinámicas de ocupación territorial de la ciudad en su conjunto. Para ello, planteamos una visión temporal y espacial que abarca el conjunto de la ciudad. La ciudad escogida es Cúcuta, que tiene la particularidad que vivió un terremoto en 1875 y que fue reconstruida de nuevo a partir de 1912. Por ello, se ha tomado esta fecha como punto de partida, hasta la actualidad, en la que cuenta con alrededor de un millón de habitantes. La aplicación del esquema evolutivo de las Formas de Crecimiento Urbano ha sido posible aplicarlo a la evolución durante un siglo de la ciudad de Cúcuta (Colombia) (Urazan, 2008). Ello fue posible gracias al acceso de la información relativa a los servicios de agua y saneamiento y a un seguimiento de vuelos fotográficos así como de información urbanística y de publicaciones periódicas que han permitido recolectar toda la información necesaria.

Se parte de la hipótesis de que hay una cristalización progresiva en el tiempo según un esquema de las formas de crecimiento urbano evolutivas, caracterizada por sucesivas interacciones de la parcelación, la urbanización y la edificación, en la que la urbanización, a través de la introducción de los servicios urbanos, es uno de los parámetros clave para la mejora de la edificación, quien a su vez permite en etapas posteriores la mejora en la legalización de la parcela como forma de capitalización de la inversión realizada. No entraremos aquí en las formas de gobernanza que permiten estos cambios. Nos centramos más en el urbs que en el civitas, en el continente que en el contenido como expresión de una condición necesaria, que no suficiente, para la calidad de vida urbana.

\section{La topología del territorio: un elemento explicativo del marco en el que se inscriben las formas de crecimiento diferenciales}

El crecimiento urbano de la ciudad de Cúcuta permite establecer que la evolución de la expansión de los distintos tejidos urbanos de la ciudad se ha regido a partir de tres núcleos o nodos: uno que corresponde al sector Centro, origen de la ciudad y de las redes de servicios, y dos núcleos cuyo origen también es formal, pero cuya localización queda separada y no hay continuidad con el núcleo Centro y conllevan tejidos en su área de influencia que han surgido debido a la existencia de estos núcleos periféricos. Es de resaltar en este sentido que los barrios que se originaron como proyectos de vivienda estatales en las denominadas ciudadelas Atalaya y San Luis ${ }^{1}$ (década de 1960) se identificaron como 

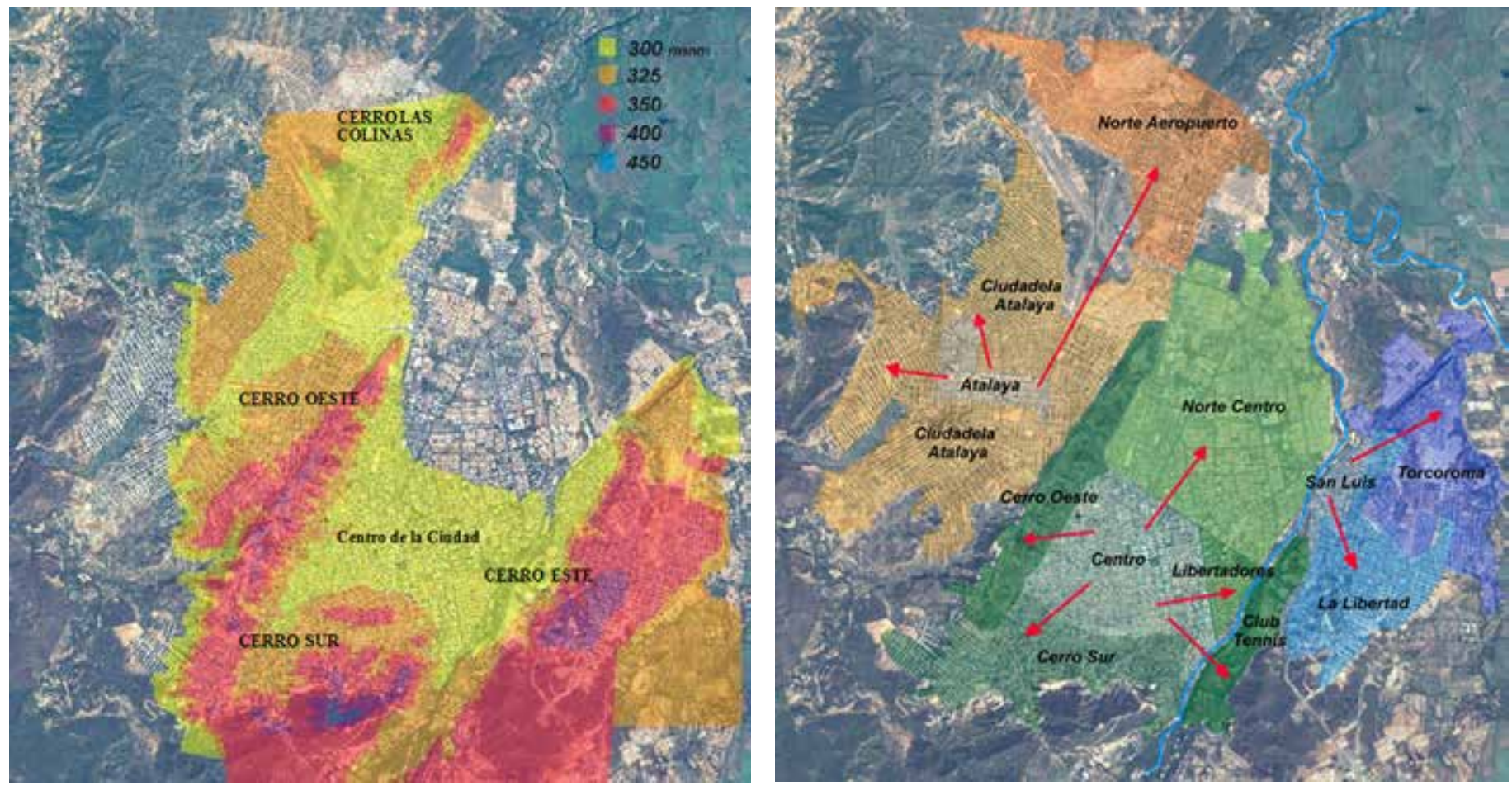

polos de atracción de asentamientos de invasión a su alrededor (ver figura 3b); hecho motivado por contar con infraestructura básica de acceso (conexión al centro comercial de la ciudad) y de servicios públicos. Por otra parte, el análisis de la evolución temporal de la extensión de la urbanización con la configuración topográfica de la ciudad (figura 3a) ha permitido establecer que los sectores con fuertes pendientes son los atractores de la informalidad.

Apoyándose en el historial de crecimiento urbano de la ciudad de Cúcuta, se han identificado 12 sectores en los que se puede diferenciar la extensión del tejido urbano. Estos sectores se distribuyen de acuerdo a los núcleos en 3 grandes zonas: una en el valle central de la ciudad, una segunda al lado Oeste del cerro Oeste de la ciudad, y la tercera al costado este del río Pamplonita (Figura 5).

De un análisis más detallado de los actores que han liderado el crecimiento de los barrios en las distintas épocas se pueden establecer cuatro grandes periodos (ver figura 4):

- 1912-1960: Crecimiento a partir del centro a través de urbanizadores privados.

- 1960-1980: Crecimiento fuera de la conurbación central a partir de las operaciones de vivienda, y servicios estatales a través del ICT en Atalaya y San Luis, y posterior crecimiento informal a su alrededor por la población recién llegada.

- 1980-1990: Renovación urbana de los sectores informales alrededor de los dos núcleos periféricos a través de la acción del Municipio y los pobladores (redes secundarias de agua y saneamiento) y de Metrovivienda (regularización de la vivienda).

- 1990-2003: Acción institucionalizada del Estado a través de INUR$\mathrm{BE}$, el municipio y Metrovivienda en los procesos de regularización de vivienda, parcelación y servicios.
Figuras 3a (izquierda) y $3 b$ (derecha) Topografía y mecanismos de crecimiento de la ciudad de Cúcuta basados en el núcleo central y los nodos periféricos de Atalaya y San Luis. Fuente: Elaboración propia. 


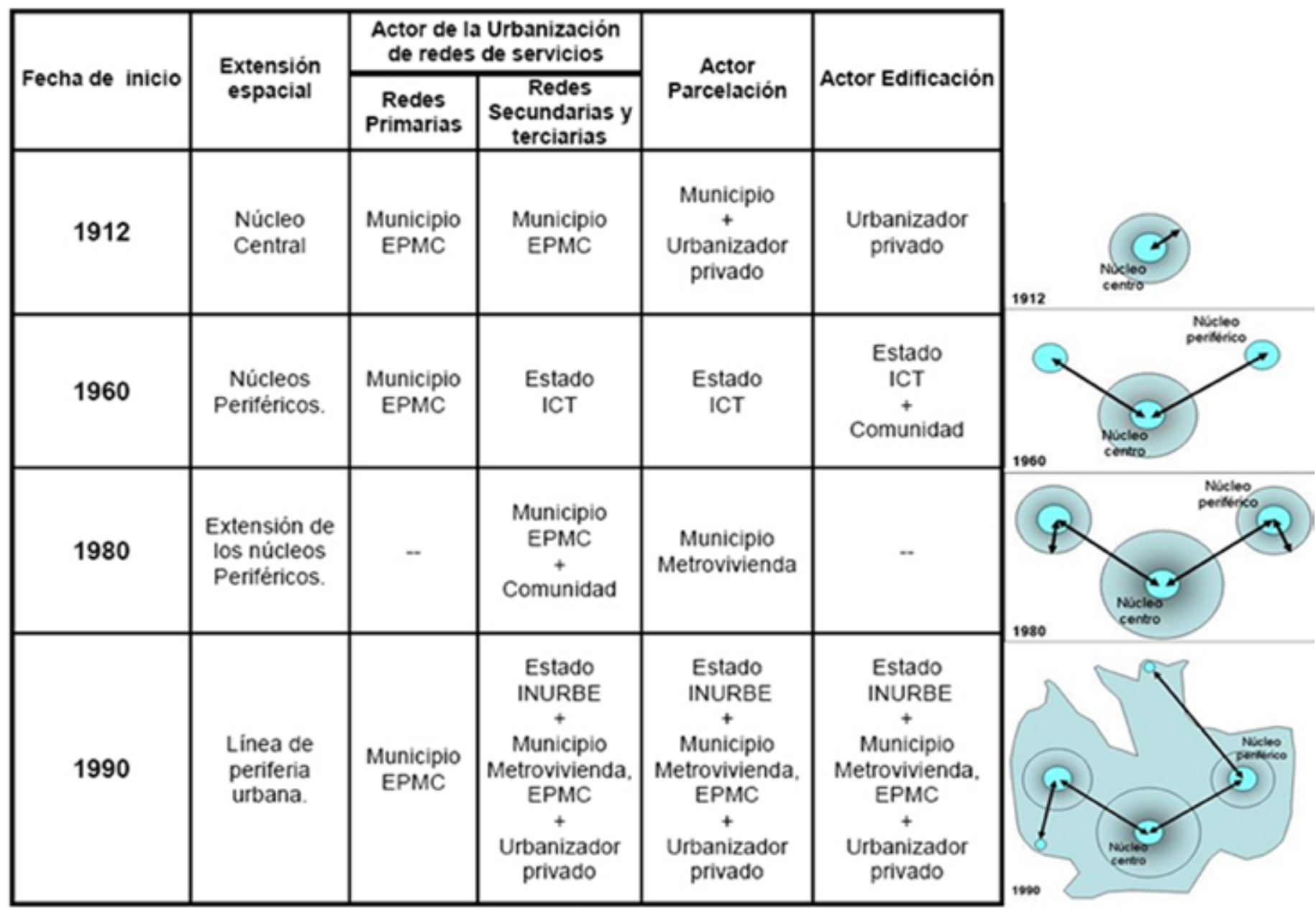

Figura 4. Esquema de desarrollo urbano y expansión de Cúcuta según operadores de las redes de servicios, de la parcelación y de la vivienda. Fuente: Elaboración propia.

2 Debido a la disponibilidad de información, los años extremos del análisis son 1912 y 2003.
Se puede establecer como conclusión que se produce una evolución de la extensión de la mancha urbana, y su dependencia de la distancia a las redes oficiales de servicios:

a) Dependencia de la distancia al Centro $\left[\mathrm{d}_{\mathrm{c}}\right]$.

b) Se mantiene la dependencia de distancia al Centro $\left[\mathrm{d}_{c}\right]$, pero a gran distancia.

c) Dependencia de la distancia al núcleo periférico $\left[\mathrm{d}_{\mathrm{np}}\right]$.

d) Dependencia conjunta entre la distancia al núcleo periférico y al Centro $\left[\mathrm{d}_{\mathrm{cr}}\right]$.

\section{La caracterización de los barrios según formalidad e informalidad y el rol de las políticas públicas}

El primer paso para construir el crecimiento histórico de la ciudad ha sido identificar la aparición o conformación de cada uno de los barrios en periodos decenales en un periodo de estudio, abarcando el periodo de un siglo. ${ }^{2}$ Como información adicional se ha registrado la condición de cada barrio según su origen: informal o formal; y si ha habido desarrollos de inversión del Estado, tal como se detalla en la figura 5.

Del análisis de estas variables se pueden establecer 6 sectores formales:

a) Sector Centro. Esta zona corresponde al desarrollo inicial de la ciudad a partir de 1875 , y se considera en esta clasificación como la 
parte sur del valle de la ciudad, entre el río Pamplonita y el cerro Oeste de la ciudad [sector Cerro Oeste]. Su urbanización se considera como desarrollo completo. Su extensión es de 440 ha.

b) Sector San Luis. Este sector corresponde al barrio San Luis. Al igual que el sector Centro, es un desarrollo que data desde el año 1875, con la diferencia de encontrarse al costado este del río Pamplonita. Su extensión es de 62 ha.

c) Sector Norte Centro. Esta zona se considera la parte Norte del valle central de la ciudad, entre el río Pamplonita y el cerro Oeste de la ciudad [sector Cerro Oes$t e$. Se conforma por proyectos urbanísticos de desarrollo completo. Se formó como continuación de la parte sur del valle central de la ciudad [sector Centro]. Su extensión es de 870 ha.

d) Sector Libertadores. Esta zona es parte del sector sur del valle central de la ciudad. Es la extensión del sector Centro hacia el río

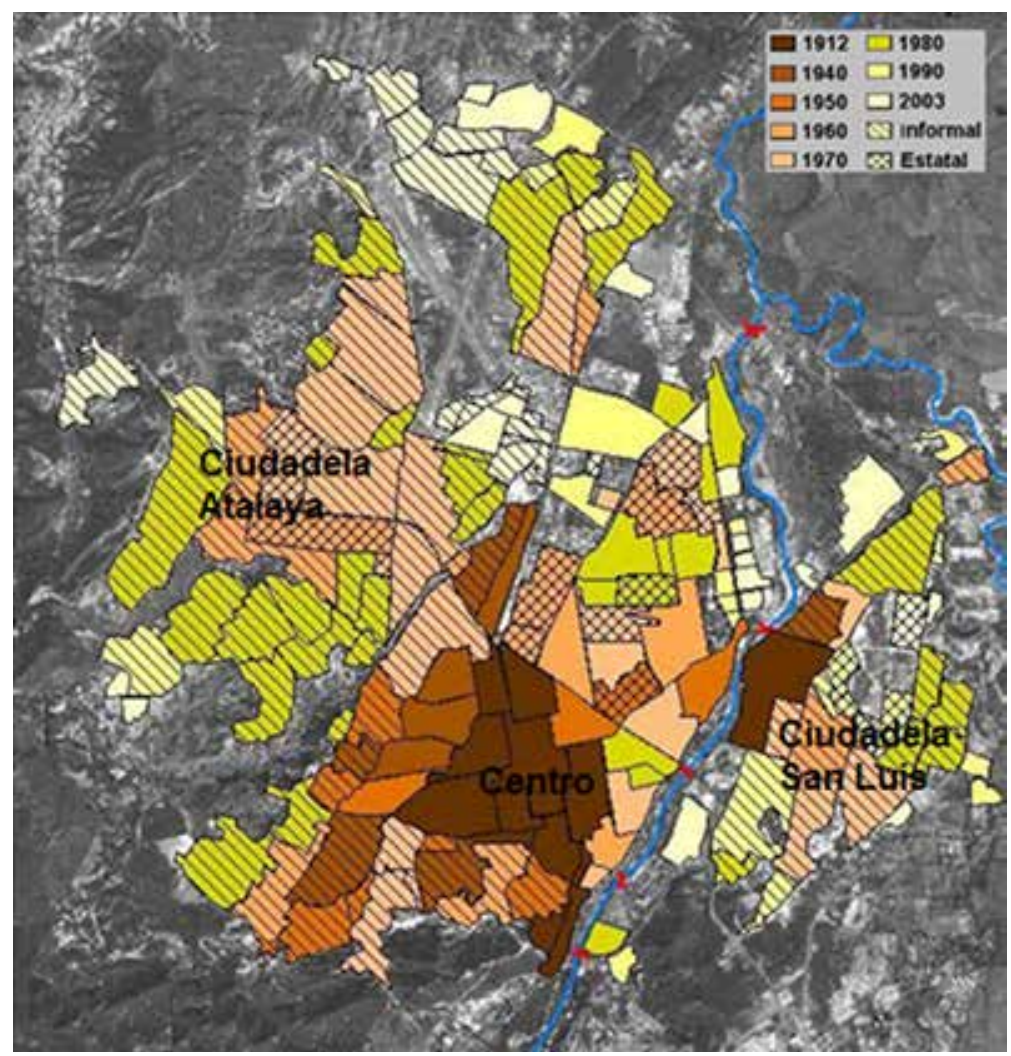
Pamplonita, y poseedor de características urbanas más modernas que el primero, conformado por actividad residencial de desarrollo completo. Su extensión es de 60 ha.

e) Sector Club Tennis. Este sector se ubica al margen este del río Pamplonita. Su conformación es de áreas de desarrollo completo. Su extensión es de 149 ha.

f) Sector Atalaya. Esta zona corresponde a los barrios: Juan Atalaya Ira etapa, Juan Atalaya $2^{\text {da }}$ etapa y Claret, construidos por el ICT. Se encuentra ubicada al oeste del cerro Oeste de la ciudad. Se considera el núcleo que propició en su entorno la propagación de desarrollos espontáneos por invasión [sector Ciudadela Atalaya]. Su extensión es de 102 ha. Este sector presenta la particularidad de presentar una politica pública de vivienda.

Respecto a los tejidos de origen informal se distingue una zona resultado de núcleos de expansión. Se compone de los siguientes 4 sectores:

a) Sector Cerro Oeste. Estos terrenos corresponden al cerro Oeste de la ciudad. Los asentamientos desarrollados en esta zona son invasiones a terrenos ejidos y debido a su difícil orografía (expresada en sus altas y escarpadas pendientes) no presenta una parcelación ordenada a manera de retícula. Su extensión es de 257 ha.

b) Sector Cerro Sur. Este sector corresponde al cerro Sur de la ciudad. Presenta similar orografía al cerro Oeste, motivo por el cual su desarrollo urbano también corresponde a invasiones a ejidos con parcelación desordenada. Su extensión es de 383 ha.

c) Sector La Libertad. Este sector corresponde al cerro Este. Al igual que los otros dos cerros, sus terrenos carecen de adecuada orografía para desarrollos urbanos. Se pobló por asentamientos de invasión, cuyo nexo urbano principal era el existente barrio San Luis [sector San Luis]. Su extensión es de 339 ha.
Figura 5. Mapa del crecimiento urbano de la ciudad de Cúcuta, 2003. Fuente: Elaboración propia. 
d) Sector Ciudadela Atalaya. Este sector es colindante al sector Juan Atalaya y se considera que su crecimiento se halla ligado a la existencia de ese sector y sus infraestructuras. Completa el área del casco urbano al lado oeste del cerro Oeste de la ciudad. Se conforma mayoritariamente por barrios originados en invasiones. Su periferia norte colinda con el aeropuerto. Su extensión es de 1203 ha.

Adicional al núcleo de origen institucional, existen otros dos sectores que cobijan desarrollos formales alrededor de los cuales se han formado asentamientos informales:

a) Sector Torcoroma. Esta zona se halla ubicada entre el río Pamplonita de la ciudad y la frontera con Venezuela. Posee condiciones orográficas más adecuadas que el cerro Este para desarrollo urbano. En este sector coexisten desarrollos habitacionales de origen espontáneo y de desarrollo completo. Entre los últimos se resalta la presencia de proyectos ejecutados por el Estado. Su origen como desarrollo urbano se halla ligado al existente barrio San Luis [sector San Luis]. Su extensión es de 467 ha.

b) Sector Norte Aeropuerto. Se ubica al noreste del aeropuerto. Es la periferia norte de la ciudad. Se halla conformado principalmente por asentamientos de invasión, aunque en su sector norte el sector edificador privado ha desarrollado proyectos de vivienda social. Su extensión es de 549 ha.

Como conclusión principal a la clasificación sectorial, las zonas que se pueden considerar como núcleos formales de crecimiento urbano son: el sector Centro en el valle central, el sector San Luis al costado Este del río Pamplonita, y el sector Juan Atalaya al occidente del cerro Oeste. Los sectores restantes se han de considerar como progresiones de los núcleos ya mencionados. Por tanto, se tiene: los sectores Oeste, Este, Norte Centro, Libertadores, Norte Aeropuerto y Club Tennis como extensiones del sector Centro, los sectores Torcoroma y La Libertad como extensiones del sector San Luis, y el sector Ciudadela Atalaya como extensión del sector Juan Atalaya (ver figura 5).

Los sectores que se pueden considerar como desarrollos formales son: Centro, San Luis, Norte Centro, Juan Atalaya, Libertadores y Club Tennis. Los desarrollos de vivienda social se encuentran en el sector Atalaya y parcialmente en los sectores Norte Aeropuerto y Torcoroma (ver figura 3). Los sectores con mayoría de asentamientos informales son los sectores Cerro Oeste, Cerro Este, Ciudadela Atalaya, Torcoroma, La Libertad y Norte Aeropuerto.

\section{De la ocupación del territorio a la densificación de los tejidos urbanos}

A partir de la cuantificación de la evolución de la extensión de la urbanización a partir de la información generada en SIG y expresada en la figura 5 se han podido elaborar las curvas de crecimiento temporal según los tipos de urbanización: urbanizador privado formal, urbanizador estatal formal y urbanizador espontáneo informal (ver figura 6).

De su análisis se observa en primer lugar el rol menor del Estado como urbanizador en cuanto a superficie desarrollada, que no llega a un $10 \%$ del total de la urbanización. De hecho, el Estado se erige como referente que marca la localización de las políticas públicas con 
los nuevos centros y que establece las formas de construcción.

Por otra parte, destaca el rol clave del desarrollo informal a partir de 1960, que se convierte en la forma principal de urbanización a partir de 1965 y que se atempera a partir de 1980. Por otra parte, se constata un crecimiento constante de las urbanizaciones formales privadas a lo largo del tiempo.

De esta forma, se pueden establecer cuatro fases:

1. Previo a 1930. Predominio del tejido Formal a través del urbanizador privado.

2. Entre 1930 y 1960. Crecimiento paralelo de los tejidos Formal e Informal.

3. Entre 1960 y 1980. Auge del tejido Informal por medio de la proliferación masiva de asentamientos espontáneos, y marcada presencia de la urbanización estatal.

4. De 1980 a 2003. Reducción del crecimiento del tejido Informal a una tasa similar a la del tejido Formal. La urbanización estatal mantuvo una tasa reducida.

Estas cuatro fases las podemos caracterizar según sea el predominio del desarrollo formal o informal. Se pueden establecer de esta forma cuatro periodos con identidades distintas (ver figura 7):

- Periodo Colonial con crecimientos de predominio formal.

- Periodo de Expansión Inicial asociado al inicio de la extensión generalizada de la urbanización informal.

- Periodo de Expansión Masiva consecuencia de la generalización del fenómeno de la urbanización, combinación de tipos formales e informales con predominio de estos últimos.

- Periodo de Substitución asociado a la formalización de tejidos a través de la mejora de servicios urbanos.
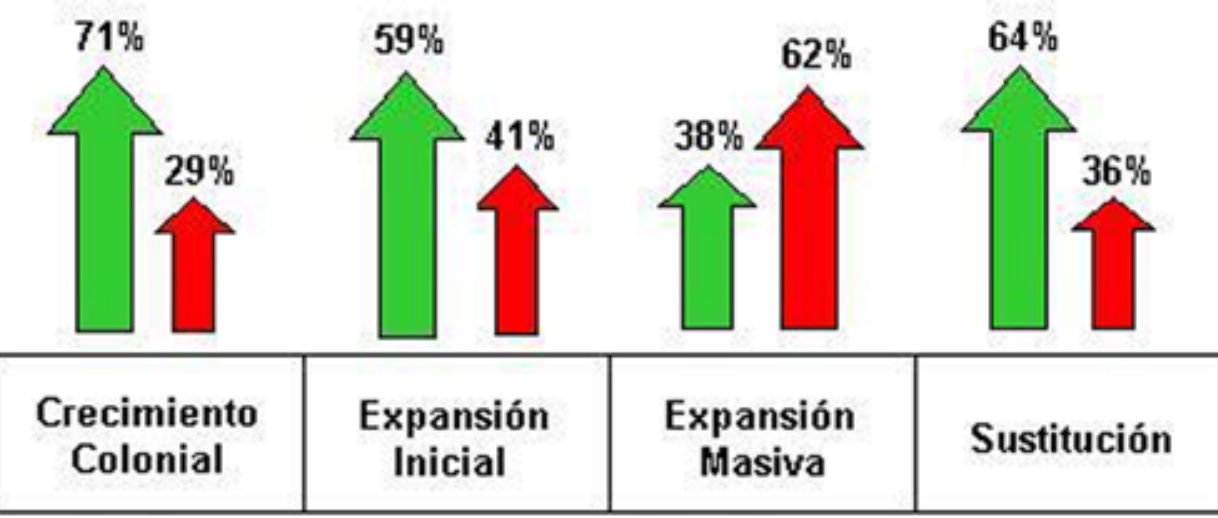

\section{Consecuencia del fenómeno dela unhanización}

Figura 7. Esquema de desarrollo urbano y expansión de Cúcuta. Fuente Elaboración propia.

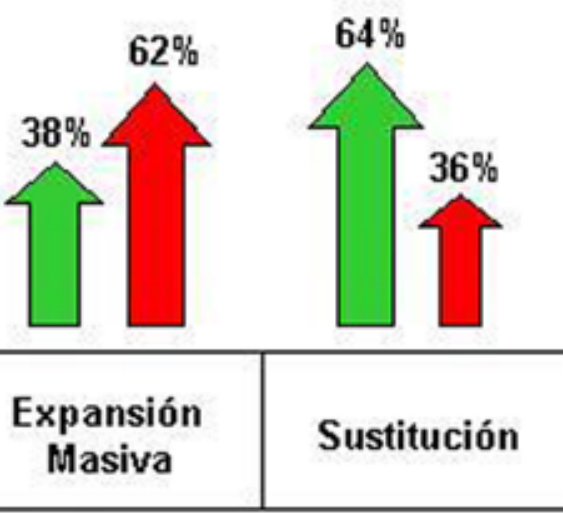

Estandanzación aplicada a la expansión generada por el fenómeno de la urhanización 
Se ha realizado un análisis paralelo consistente en comparar la extensión de la urbanización y de la población (ver figura 8). De este análisis se constata que respecto de la situación final (actual), los niveles de crecimiento en la extensión de la urbanización se avanza a los niveles de crecimiento de la población. Se puede afirmar que la extensión de la urbanización se avanza como inversión en capital fijo con bajas demandas de calidad de la urbanización que posteriormente se recupera con un proceso de densificación de los tejidos urbanos. Se produce, de hecho, un fenómeno de acordeón entre crecimien-

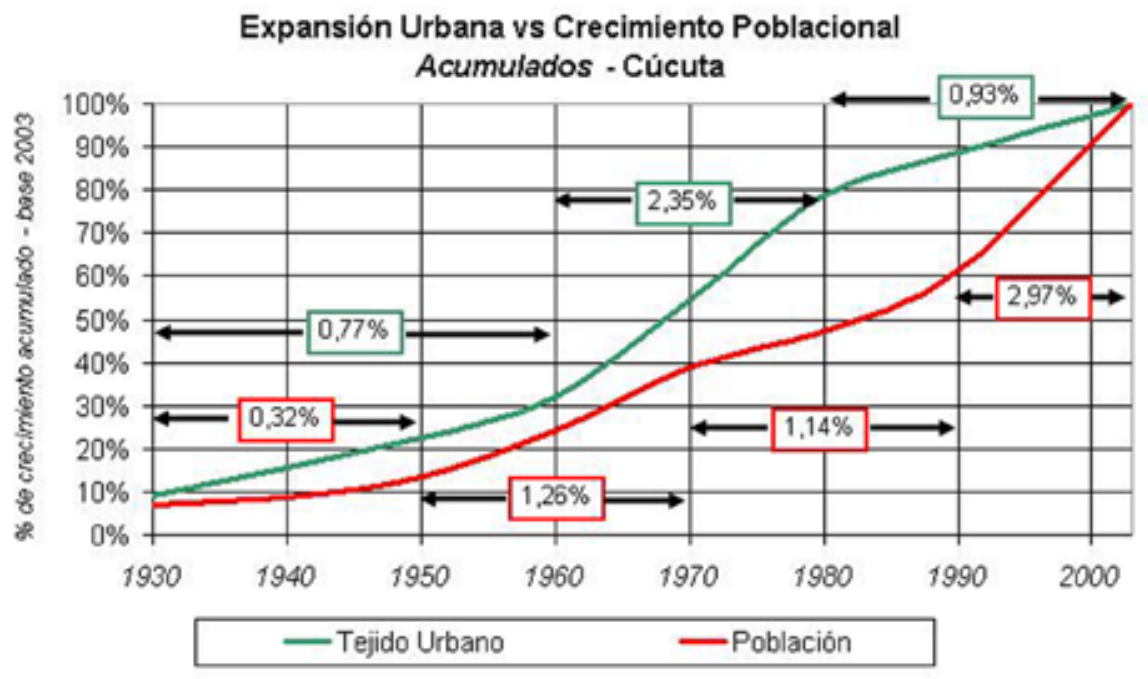
tos de tejido urbano y crecimientos de población que se encabalgan. De 1930 a 1960 crece de forma predominante el tejido (0,32\% anual); de 1950 a 1970 crece la población (1,26\% anual); de 1960 a 1980 crece el tejido urbano (2,35\% anual); de 1970 a 1990 crece la población (1,14\% anual); luego vuelve otra vez el crecimiento de tejido urbano (0,93\% anual); para crecer otra vez la población de 1990 a $2000(2,97 \%$ anual). Los crecimientos máximos anuales de ocupa-

Figura 8. Evolución de las superficies de expansión y la población acumulada en Cúcuta (Colombia). Fuente: Elaboración propia. ción de ciudad se producen en el periodo 1960-1980, mientras que los de población se producen en la etapa final de 1990-2000, que es el momento de legalización y de densificación máximo del tejido urbano.

\section{Caracterización de la evolución en la extensión de los servicios urbanos y sus correlaciones con la urbanización}

Una vez establecidos los mecanismos de extensión de la urbanización y de sus actores vamos a definir cuál es el rol de los distintos servicios urbanos en la correlación con la evolución de la parcelación y de la edificación. El paso a seguir es el de conocer la extensión de las redes de abastecimiento de agua, de saneamiento y la de pavimentación, en tiempo y espacio, con el fin de poder identificar la presencia de las redes en cada sector y periodo, y así asignarle a cada barrio de la ciudad las tipologías de la urbanización de servicios que le corresponde $\left[\mathrm{U}_{\mathrm{a}}\right.$, $\mathrm{U}_{\mathrm{s}}, \mathrm{U}_{\mathrm{p}}$ ]. Las figuras 9, 10 y 11 exponen la extensión cronológica de las tres redes, respectivamente.

En ellas se observa que tanto para la extensión de la red de agua como de saneamiento (ver figuras 9 y 10) fue clave la extensión de los troncos principales de la red en su salto a los nodos periféricos de Atalaya y San Luis. Esta inversión en capital fijo implicó una gran inversión que permitió un salto de umbral a partir de 1960. Las inversiones en redes en este periodo fueron fundamentales para el crecimiento posterior de las redes secundarias y terciarias de agua y saneamiento. La inversión en la década de 1960 se centró en la construcción de depósitos e impulsiones pasa saltar al otro lado de los cerros y del río Pamplonita. 

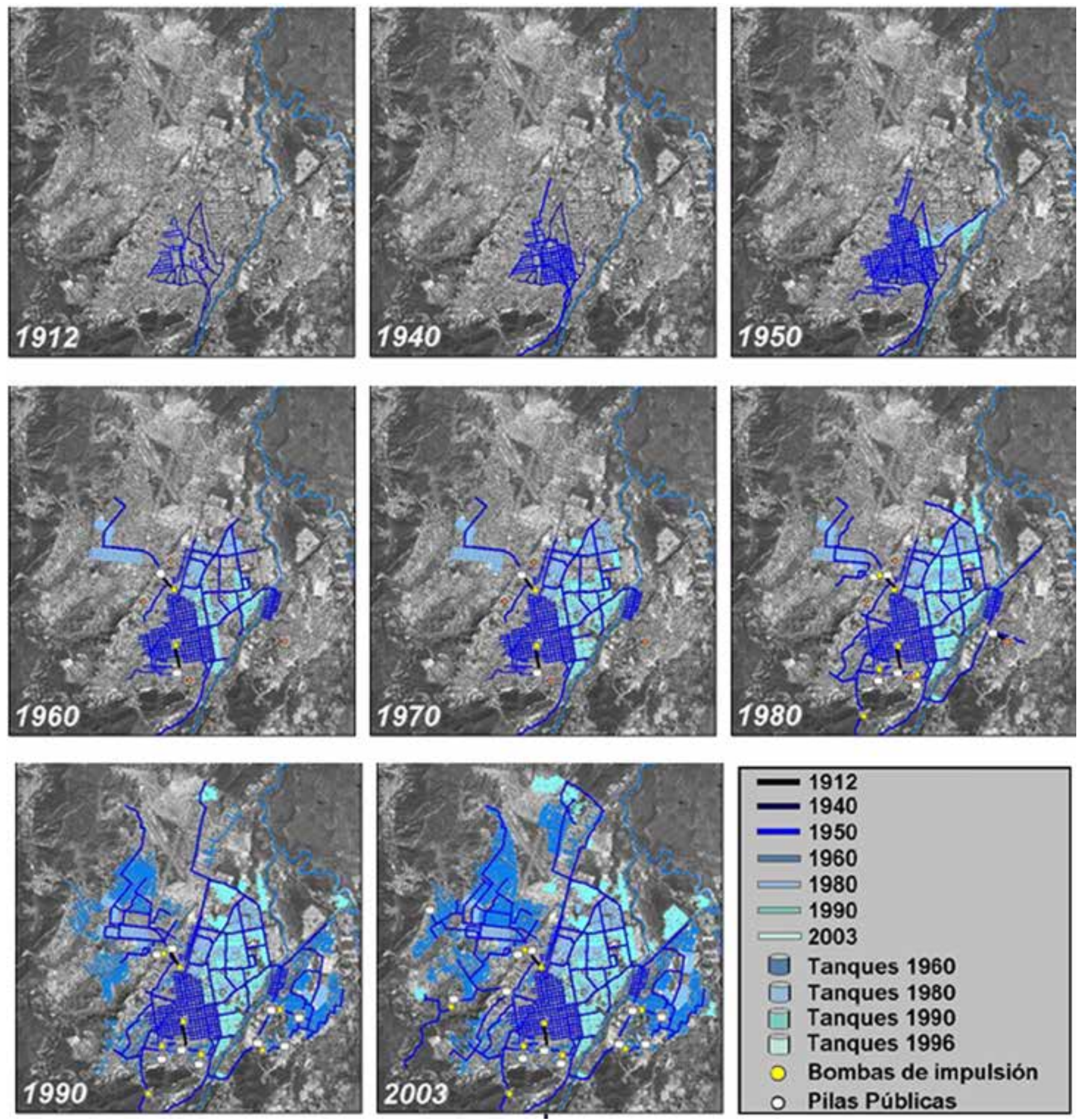

Lo mismo sucedió en el caso de la pavimentación, donde sobre la base de una red de empedrado en la zona central y la extensión de urbanización en macadam en los nodos periféricos se extendió la tecnología pavimentación con tierra y la interconexión de los nodos principales con pavimento asfáltico. Posteriormente se produjo una substitución de pavimentos en tierra por pavimentos en concreto u hormigón (ver figura 11). Cabe señalar, en conjunto, un crecimiento continuado del pavimento asfáltico que en cualquier caso es minoritario.

$\mathrm{Al}$ sobreponer los mapas de crecimiento de barrios y los de las redes de los tres servicios urbanos (ver figura 12) se observa que las redes se iniciaron en la zona centro de la ciudad, y que acompañaron el $78 \%$ del área desarrollada en ese momento. Luego, en la década de 1940 se

Figura 9. Extensión de la red oficial de abastecimiento de agua en la ciudad de Cúcuta. Fuente: Elaboración propia. 

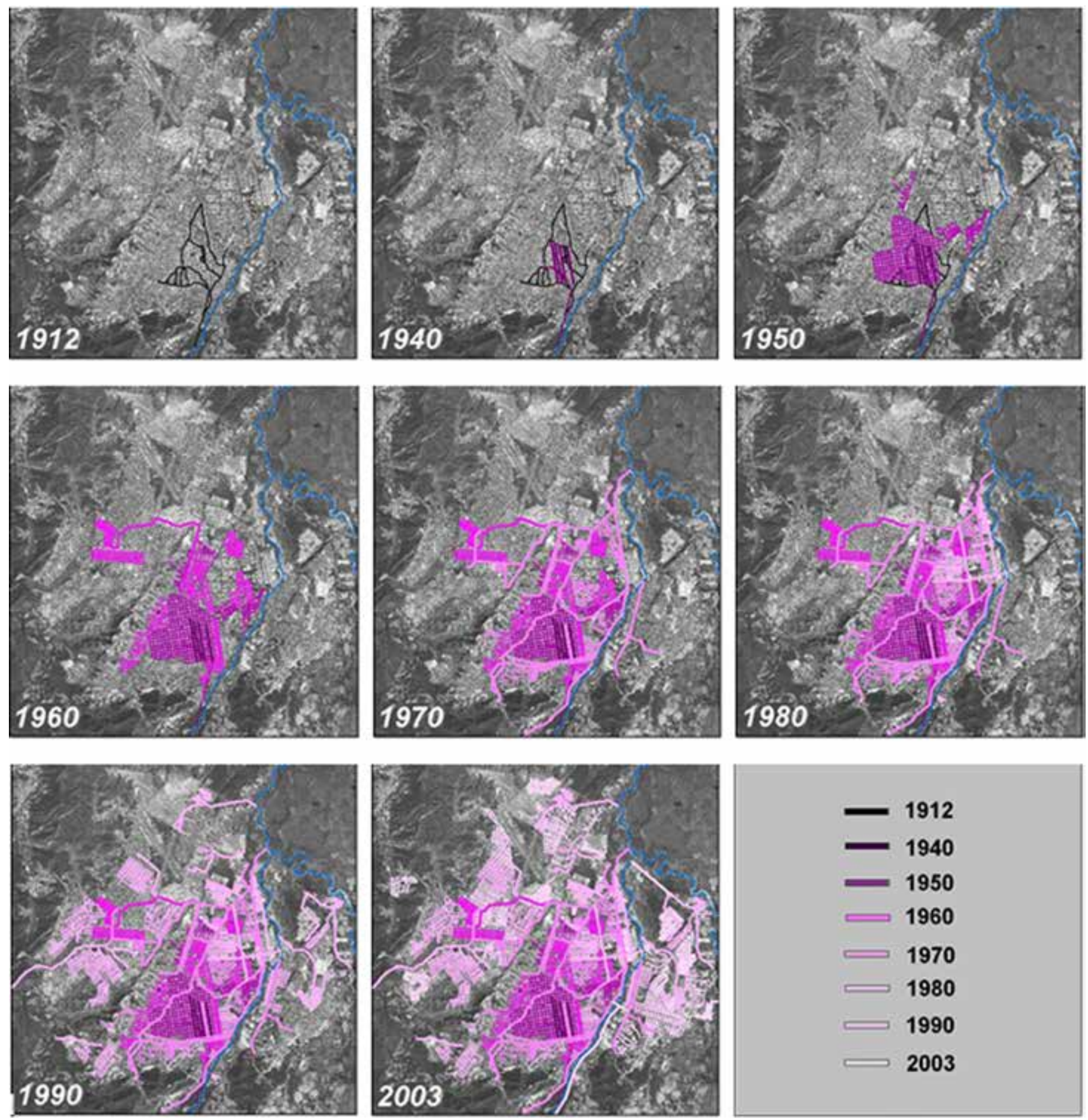

Figura 10. Extensión de la red oficial de saneamiento en la ciudad de Cúcuta. Fuente: Elaboración propia.

3 Barrio que contaba con las redes de servicios públicos domiciliarios de abastecimiento de agua, saneamiento y energía eléctrica, al igual que la red vial que lo conectaba con la zona centro de la ciudad. Era el primer desarrollo al costado occidental del "cerro occidental" y aprovechaba la ventaja de ser un proyecto en condiciones formales.

inició la aparición de invasiones en los cerros occidental y sur. En este escenario las redes de agua y saneamiento continuaban sirviendo solo a los sectores formales, por lo cual la cobertura de las redes se redujo al $64 \%$ de la mancha urbana. Una década después, en 1950, empezaron a extenderse las redes de agua y saneamiento en la zona del cerro occidental, acompañando brevemente la aparición de los barrios informales originados en la década anterior.

En la década de 1960 se inició el desarrollo de la construcción del barrio de vivienda social del estado "Juan Atalaya" y la extensión de las redes de agua y saneamiento al barrio San Luis. ${ }^{4}$ Los sectores formales continuaron creciendo al norte, pero el crecimiento de barrios informales fue superior al de la extensión de las redes de servicios que en ese momento ya solo cubrían el 55\% del área urbana. 

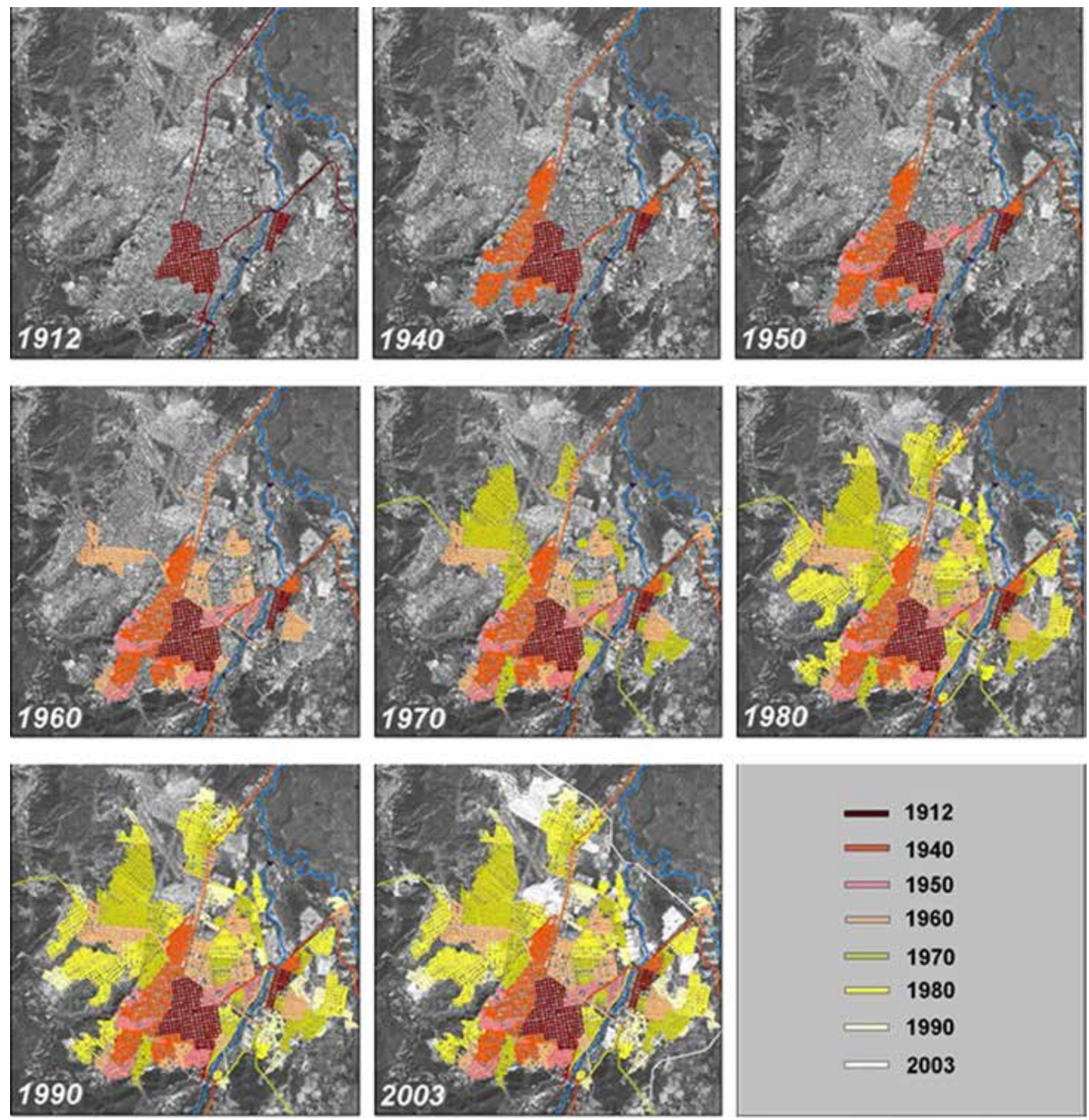

En la década de 1980 se registró un máximo en la expansión de los barrios de origen informal en los alrededores de las ciudadelas, obteniendo el mayor registro de todo el periodo estudiado. Las redes de servicios públicos no servían a estos barrios y ello hizo que la proporción de cobertura de las redes oficiales respecto de la mancha urbana se redujera al 48\%. Fue en la década de 1990 cuando se aprecia una recuperación en la extensión de las redes de servicios públicos oficiales a gran parte de los barrios de origen informal situados a los alrededores de las ciudadelas. En ese momento la cobertura espacial de las redes de servicios se recuperó al 78\%. Al iniciar la década de 2000 disminuyó la tasa de crecimiento de los sectores informales en la mancha urbana y la cobertura de las redes de servicios alcanzó a cubrir el 90\%

Figura 11. Extensión de la red de pavimentación en la ciudad de Cúcuta. Fuente: Elaboración propia.

4 Existente desde principios de siglo, pero que por su lejanía de la zona centro y estar ubicado al otro lado del río Pamplonita, no contaba con redes de servicio público. 

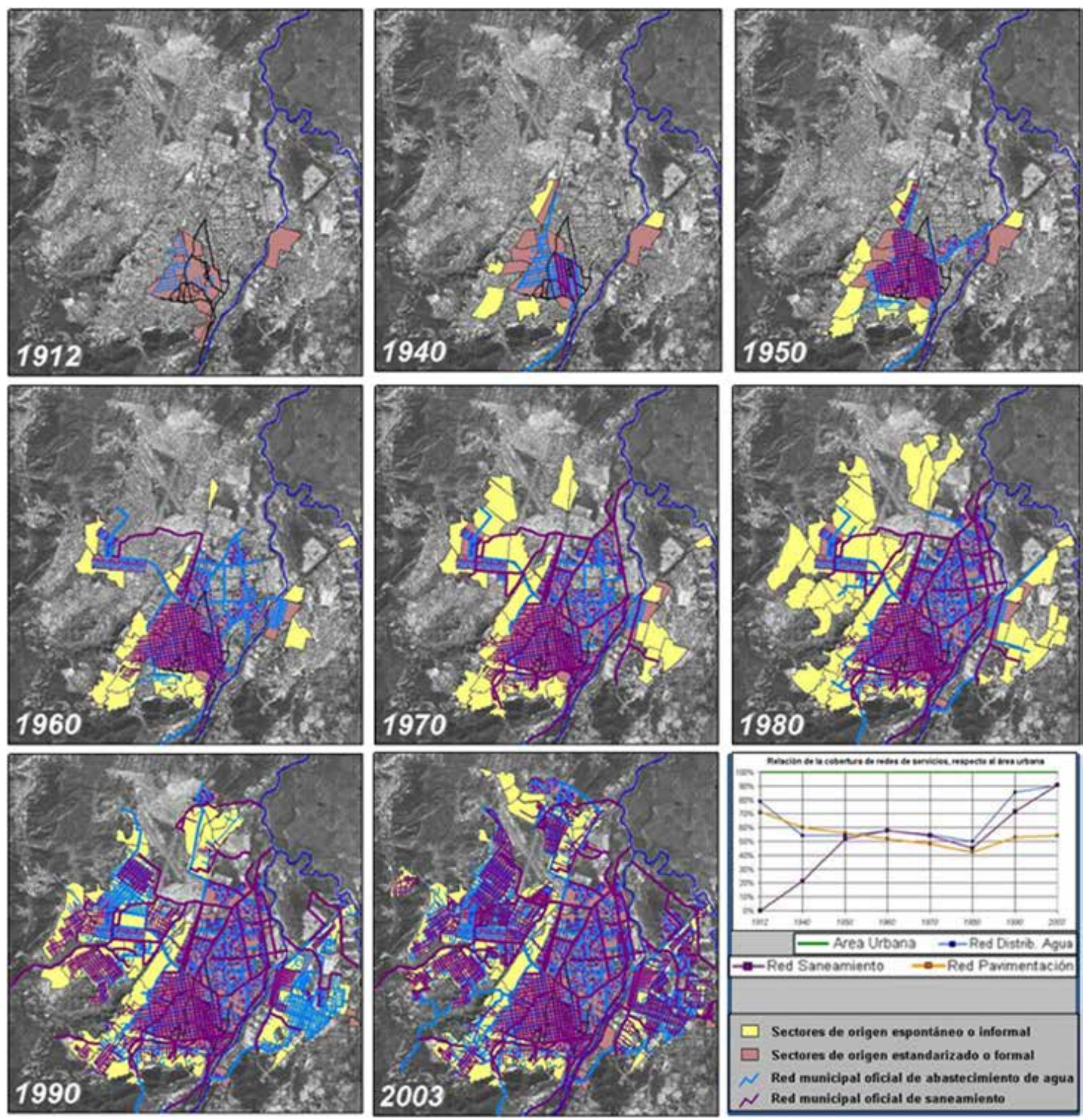

Figura 12. Extensión de las redes de agua y saneamiento y de la extensión de la urbanización en la ciudad de Cúcuta. Fuente: Elaboración propia.

del mapa de la ciudad, incluyendo tanto a los sectores formales como a los informales.

Existe, pues, un mecanismo elástico en el que los sectores informales desarrollan en sus inicios sistemas autónomos o ilegales con servicios mínimos de abastecimiento y accesibilidad. Posteriormente, estos sectores se transforman para llegar a conseguir servicios con niveles estándares.

En el caso de la red de abastecimiento de agua se contó con una primera fase entre 1912 y 1940, en la que la red creció a solo 2 ha/año, mientras que la mancha urbana lo hizo a 10 ha/año debido al crecimiento de los sectores informales. Por su parte, el remplazo de las vías empedradas por la red vial pavimentada en asfalto hizo que la red vial pavimentada creciera a 5 ha/año. 
Entre 1940 y 1960 se generó una segunda fase en la que la red de saneamiento entró a participar a 33 ha/ año, ritmo superior al de la red de agua, que crecía a 22 ha/año. El mayor incremento de la red de saneamiento se debió al intento por cobijar el total de los sectores formales existentes en ese momento, que ya contaban con la red de agua. La red vial tan solo creció a 16 ha/ año en este periodo, extendiendo la red primaria e iniciando su rezago respecto a las redes de agua y saneamiento.

En una tercera etapa entre 1960 y 1980 la extensión del tejido urbano creció notoriamente a $98 \mathrm{ha} / \mathrm{año}$ como resultado de la gran generación de sectores informales. Pero esos sectores informales no implementaron las redes oficiales de agua y saneamiento en este periodo, motivo por el que su ritmo de expansión fue de menos de la mitad que el tejido urbano: 43 ha/año y 36 ha/año, respectivamente, para cada servicio. Con una tasa similar, la red secundaria vial pavimentada aumentó a 35 ha/ año. Al finalizar este periodo la cobertura de las 3 redes de servicio era muy similar entre sí, con un registro aproximado a las 1500 ha.

Finalmente, entre 1980 y 2003 la extensión urbana redujo su ritmo a 39 ha/año, circunstancia que facilitó a la red de agua el aumentar a 154 ha/año en la década de 1980, superando la cobertura de la red de saneamiento, que creció a 118 ha/año. A partir de 1990 la situación cambió y fue la red de saneamiento la que aumentó a 86 ha/año y la red de agua redujo su tasa a 47 ha/año, para en 2003 contar ambas redes con coberturas del $90 \%$ del área urbana. En esta cuarta etapa el distanciamiento entre la cobertura de la red vial pavimentada (red terciaria) y la de saneamiento se hizo mayor, pues la primera red creció a solo 36 ha/año.

Se tiene, por tanto, que la red de agua aceleró su expansión respecto a la de saneamiento entre 1970 y 1990. A partir de 1990, una vez formalizada la red de agua, inició el mismo mecanismo la red de saneamiento, que creció a mayor ritmo que la del agua hasta equilibrar la cobertura de las dos redes en 2003. Por su parte, la red de pavimentación se rezagó a las de agua y saneamiento, con menor diferencia entre 1960-1980 y con mayor diferencia entre 1980-2003. El retraso de la red de pavimentación se debió a que esta solo fue aplicada en las vías principales. La figura 13 muestra este proceso evolutivo.

\section{La interacción entre la evolución de la urbanización y la evolución de la legalización predial}

Para poder determinar la interacción evolutiva entre la parcelación, la urbanización y la edificación se han planteado los niveles de servicios y los grados de parcelación y edificación en la ciudad de Cúcuta. Para ello se han tenido que definir las tipologías de $\mathrm{P}$, de U y de E; lo cual

Figura 13. Expansión urbana y de las redes de servicios de abastecimiento de agua, saneamiento y pavimentación llas cifras en los recuadros corresponden a tasas de expansión en ha/año). Fuente: Elaboración propia. 
Figura 14. Esquema evolutivo de las Formas de Crecimiento Urbano aplicado al caso de Cúcuta (Colombia). Fuente: Urazan, 2008. requiere del previo análisis de la extensión evolutiva del tejido urbano y de las redes de servicios a analizar (agua, saneamiento y pavimentación).

Una vez se ha reconstruido el crecimiento de la ciudad decenalmente a lo largo del siglo XX, tomando como unidad geográfica los barrios de la ciudad, se ha asociado una condición de PUE para cada barrio en cada momento, desde la década de su formación. De este análisis se observa que la condición de PUE para cada barrio no era constante con el paso del tiempo, por lo cual se han definido categorías evolutivas para cada acto de urbanización: Parcelación (P), Urbanización con servicios (U), Edificación (E):

- Parcelación: [Ilegal en Pendiente] [P1], [Ilegal en Llano] [P2], [Legal de Baja Densidad] [P3] y [Legal de Alta Densidad] [P4].

- Urbanización: divididas en los 3 servicios públicos estudiados:

- Abastecimiento de agua [Uai]: [Fuentes naturales] [Ua1], [Sistemas Autónomos y/o ilegal] [Ua2], [Coexistencia de conexión legal e ilegal a la red oficial] [Ua3] y [Conexión legal a la red oficial] [Ua4].

- Saneamiento [Usi]: [Sistemas autónomos] [Us1], [Coexistencia de conexión a la Red Oficial y Sistemas Autónomos] [Us2] y [Conexión legal a la red oficial] [Us3].

- Pavimentación [Upi]: [En tierra] [Up1], [Macadam] [Up2], [Pavimento en concreto] [Up3] y [Pavimento asfáltico] [Up4].

- Edificación [Ei]: [Edificación con Autoconstrucción Total No estandarizada] [E1], [Edificación con Autoconstrucción Total Estandarizada] [E2], [Edificación con Autoconstrucción Parcial Estandarizada] [E3] y [Edificación Sin Autoconstrucción y Estandarizada] [E4].

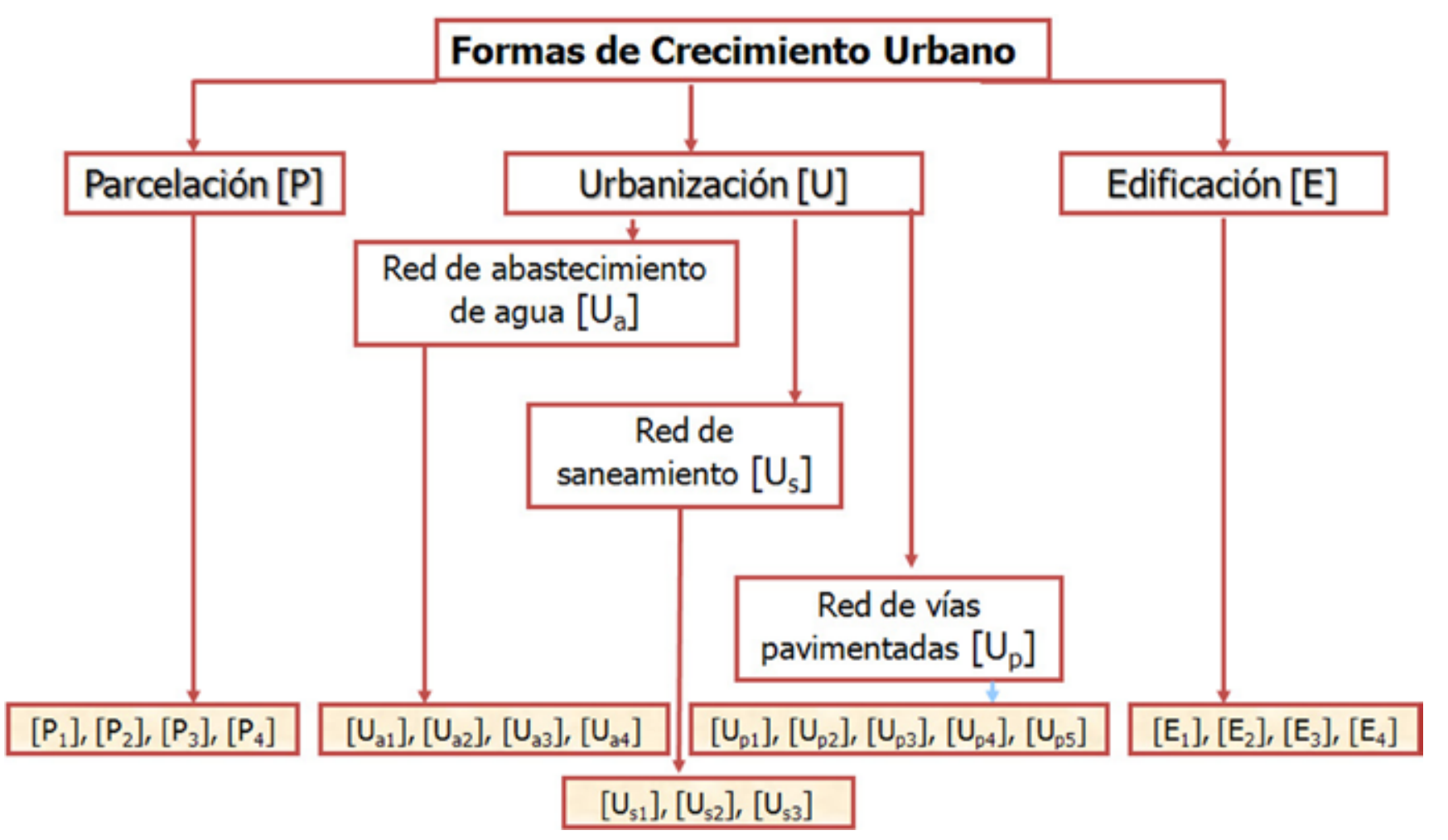


Tipologías de Parcelación [P]

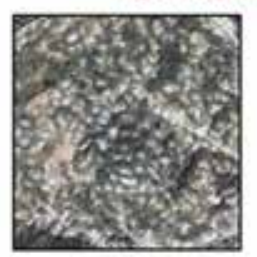

[P1] Ilegal en pendiente

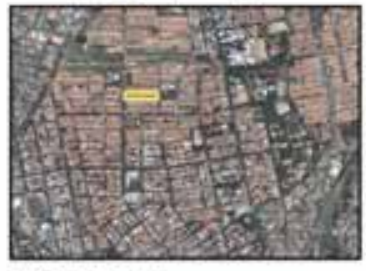

[P3] Legal de baja densidad

Tipologías de Abastecimiento de agua [Ua]
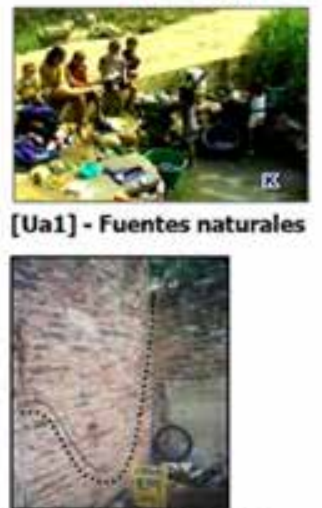

[Ua3] - Conexión legal eilegal a la red oficial
[Ua1] - Fuentes naturales conexión ilegal a la red oficial

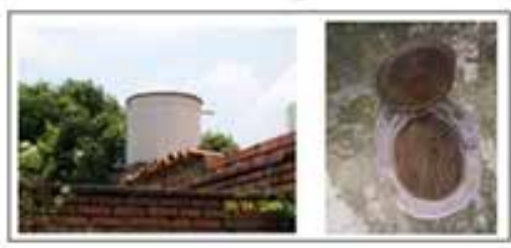

[Ua4] - Conexión a la red oficial
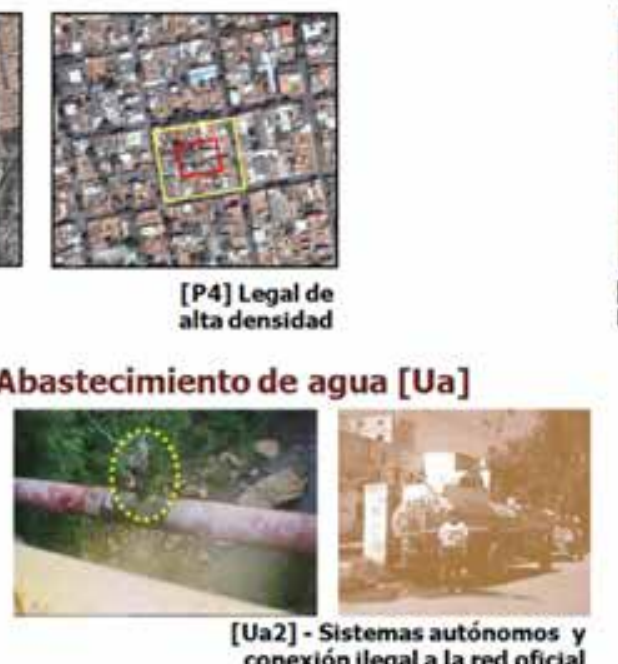

[P4] Legal de alta densidad
Tipologías de Edificación [E]

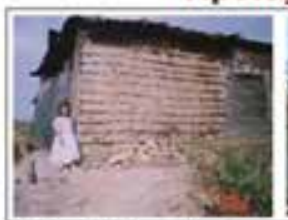

[E1]-Edificación Con A

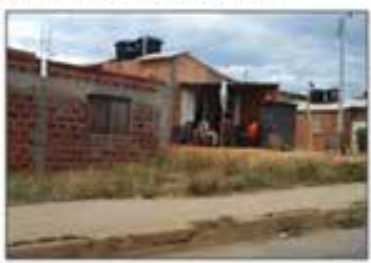

[E3] - Edificación Con Autoconstrucción Parcial Estandarizada

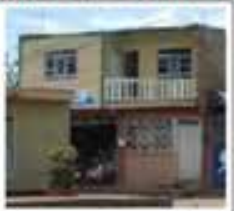

trucción

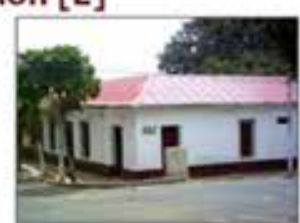

[E2] - Edificación Con ón Total Estandarizada
Tipologías de Saneamiento [Us]

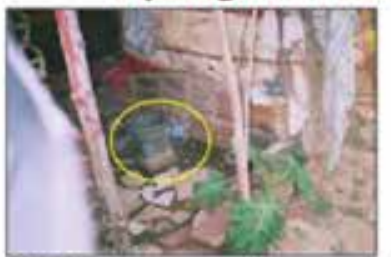

[Us1]-Sistemas autónomos

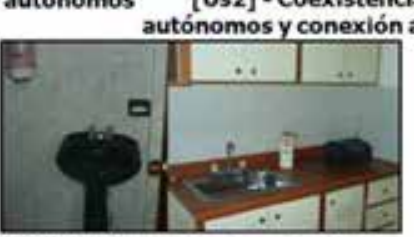

[Us3] - Conexión a la red oficial

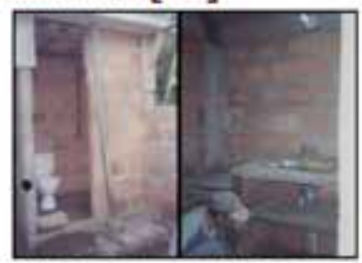

[Us2] - Coexistencia de Sistemas

[E4]-Edificación Sin [E4]-Edificación Sin
Autoconstrucción Estandarizada

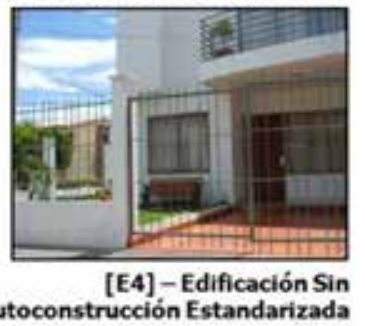


Figura 16. Mecanismo evolutivo de las Formas de Crecimiento Urbano aplicado al caso de Cúcuta (Colombia). Fuente: Urazan, 2008.
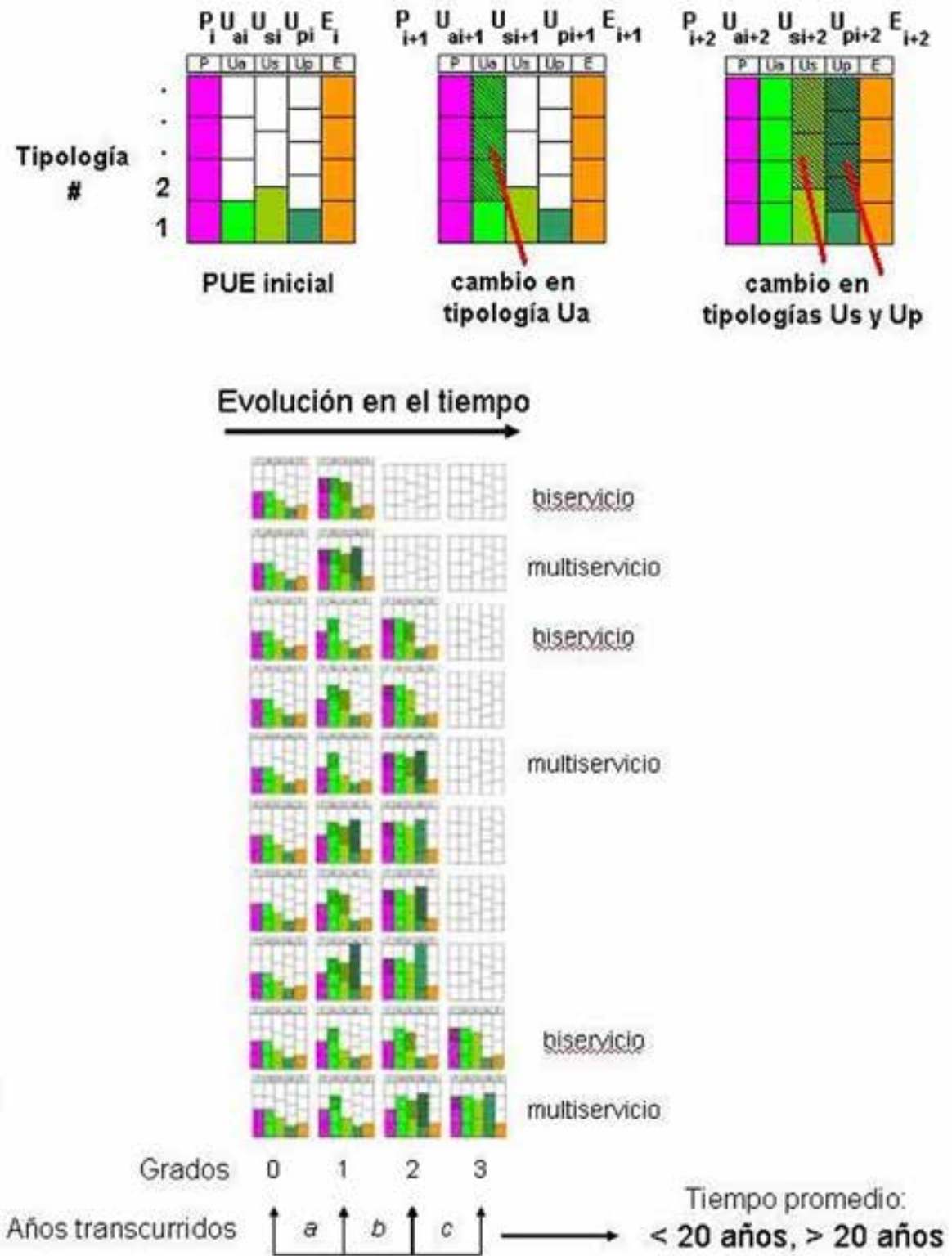

rrios de la ciudad y que han quedado recogidas de forma exhaustiva en la figura 17.

En el proceso de formalización se distingue de aquellas formas de crecimiento urbano evolutivas (FCUe) en las que existe un cambio en la parcelación de aquellas que no. Se consideran FCUe en formalización aquellas que han tenido un cambio en la Parcelación. Se consideran FCUe potencialmente formalizables aquellas en las que en un tiempo razonable, y por sí mismas, sean capaces de legalizar la parcelación. Finalmente, se consideran como FCUe Informales aquellas formas de crecimiento urbano que no se van a legalizar, a no ser que exista una gran inversión en urbanización por parte de la administración (ver figura 7). Cabe señalar que los periodos de evolución se sitúan alrededor de los 20 años como umbral que caracteriza las transformaciones.

Cada barrio o sector tiene en su inicio una tipología de $[\mathrm{P}],[\mathrm{U}]$ y [E], que en su conjunto caracterizan un [PUE] parcial. Con el pasar del tiempo las tipologías de la $[\mathrm{P}],[\mathrm{U}]$ o $[\mathrm{E}]$ pueden evolucionar o no, llegando a generar un [PUE] evolutivo. La evolución del [PUE] es la que define la FCU evolutiva del sector:

- Formal. Identifica a sectores que desde su origen han contado 


\section{FCUe Formal}

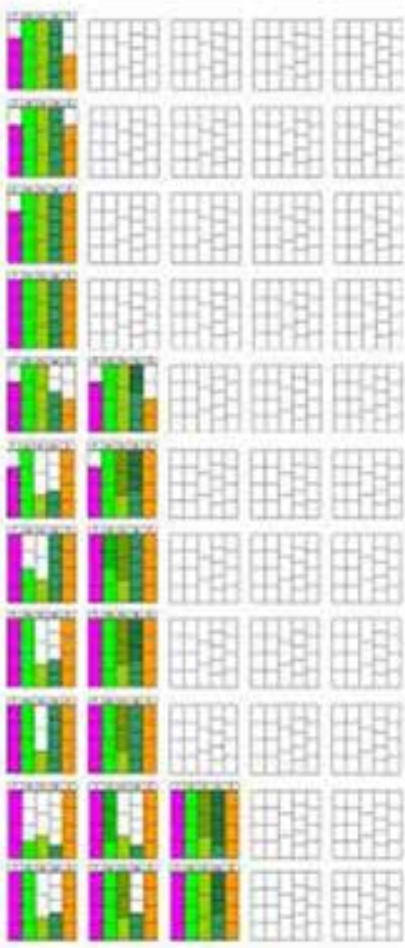

FCUe En Formalización

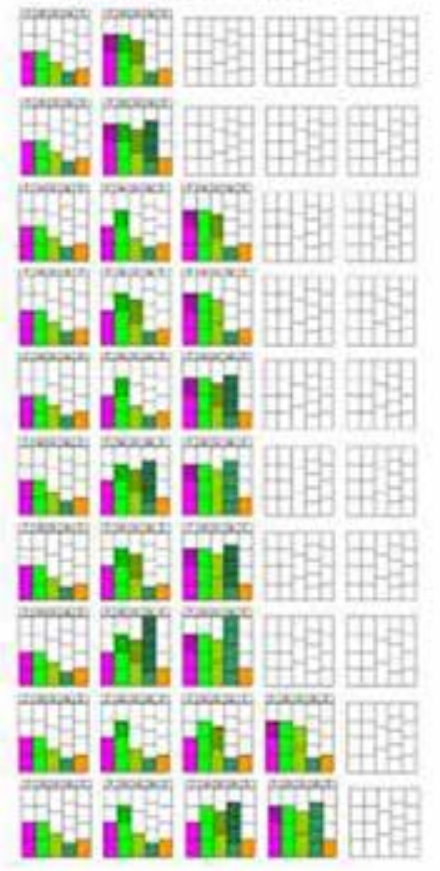

con una condición estandarizada para la parcelación, edificación y redes de servicios.

- En Formalización. Corresponde a aquellos sectores de origen informal que al momento de ser evaluados ya contaban con condiciones estandarizadas de parcelación y redes de servicios.

- Potencialmente Formalizable. Cataloga a sectores de origen informal que si bien al momento de ser evaluados no presentaban características estandarizadas de parcelación, sí poseen condiciones que los hacen candidatos a ser catalogados como FCU [En Formatización].

- Informal. Describe a sectores que cuentan con características (orográficas) que difícilmente les permitirá catalogarse como FCU [Potencialmente Formalizable].

Se ha constatado, en el caso de Cúcuta, que las FCU Formal e Informal presentan un desarrollo máximo en dos etapas evolutivas, mientras que las $\mathrm{FCU}_{\mathrm{e}}$ En Formalización y Potencialmente formalizable llegan a registrar hasta 3 etapas evolutivas.

\section{FCUe Informal}

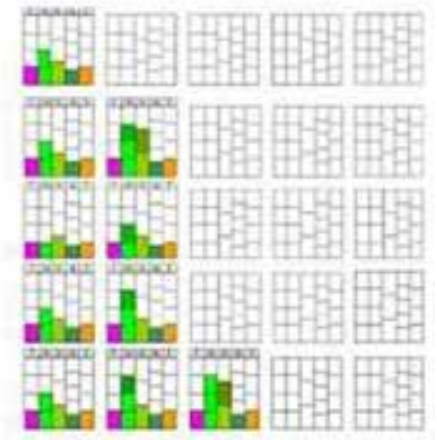

Figura 17. Procesos iterativos en la evolución de las Formas de Crecimiento Urbano Evolutivas en Cúcuta (Colombia) (Urazan, 2008). 
Figura 18. Ejemplificación de un esquema de interpretación del desarrollo evolutivo de las Formas de Crecimiento Urbano Evolutivas. Fuente: Elaboración propia.
FCUe Formal, sin evolución

P1 Ua1 Us1 Up1 E1

FCUe Formal, con evolución
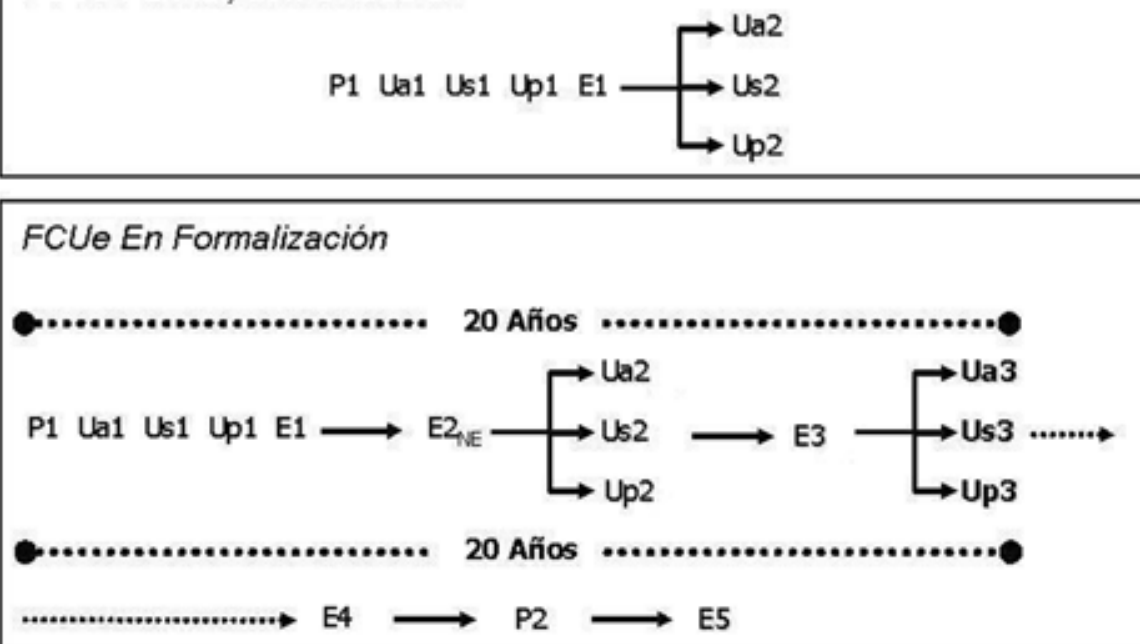

FCUe Potencialmente Formalizable

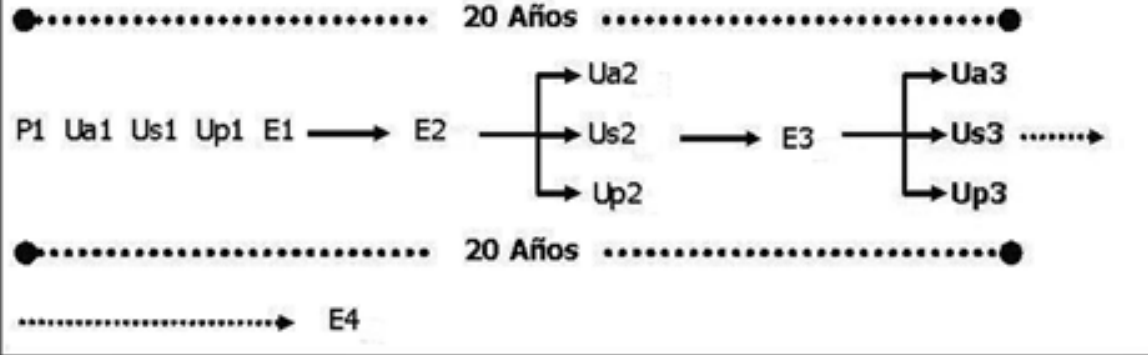

FCUe Informal, sin evolución

P1 Ua1 Us1 Up1 E1

FCUe Informal, con evolución

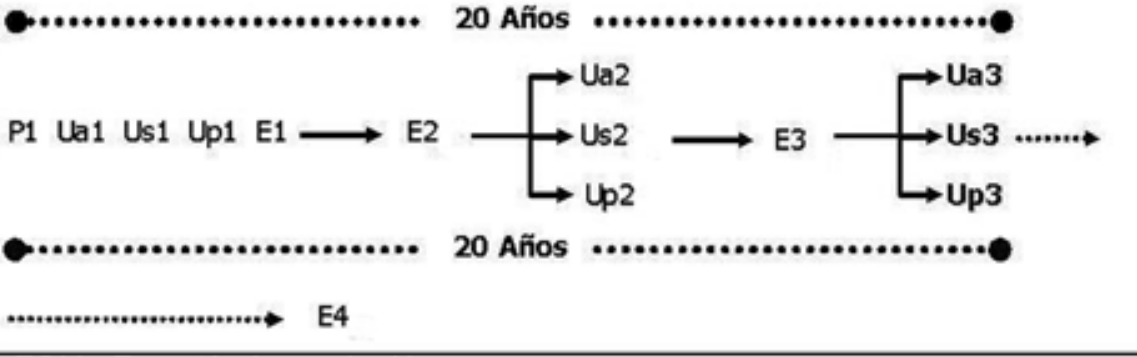

9. Las interacciones temporales entre Parcelación, Edificación y Urbanización

Continuando con el planteamiento del esquema PUE, se analizó la evolución de las tipologías de parcelación planteadas, de manera similar al estudio de las redes de servicios públicos domiciliarios (Figura 20).

La figura 5 permitió establecer la condición de legalidad de los sectores en el momento de su origen. Los registros de legalidad de asentamientos en la ciudad facilitaron reconocer aquellos que habían pasado de informal a formal y en qué momento. Ese cambio se observa entre la década de 1990 a 2000, posterior a la entrada de las redes de servicios públicos básicos. 
Del análisis comparativo de todos los servicios con la lectura de la presencia de cada nivel de servicio se observa que la edificación fue creciendo de forma avanzada y con un mayor volumen que los otros elementos, y en especial la edificación con autoconstrucción no estandarizada (informal) (ver figura 19). Este proceso va acompañado con sistemas autónomos y de conexión ilegal a las redes existentes de agua y saneamiento, así como con un sistema de accesibilidad asegurado por vías de tierra. Este proceso se inició en la década de 1940 de forma significativa, se desarrolló de forma masiva a partir de 1960, llegando a su máximo en 1980. A partir de ese momento los tejidos informales transformaron sus redes de agua, saneamiento y pavimentación, aunque el servicio de la red de agua legalizada se extendió más rápidamente que
Figura 19. Evolución combinada de las superficies de expansión según elementos de urbanización (Parcelación, Urbanización - Agua, Saneamiento, Pavimentación - y Edificación) según tipologías evolutivas. Fuente: Elaboración propia.

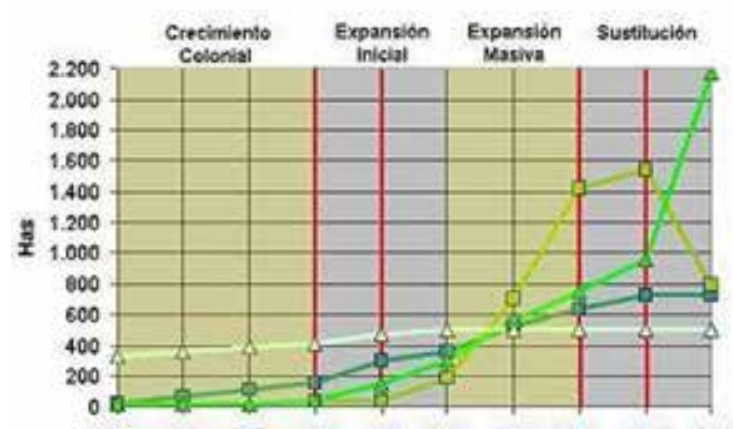

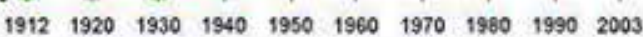
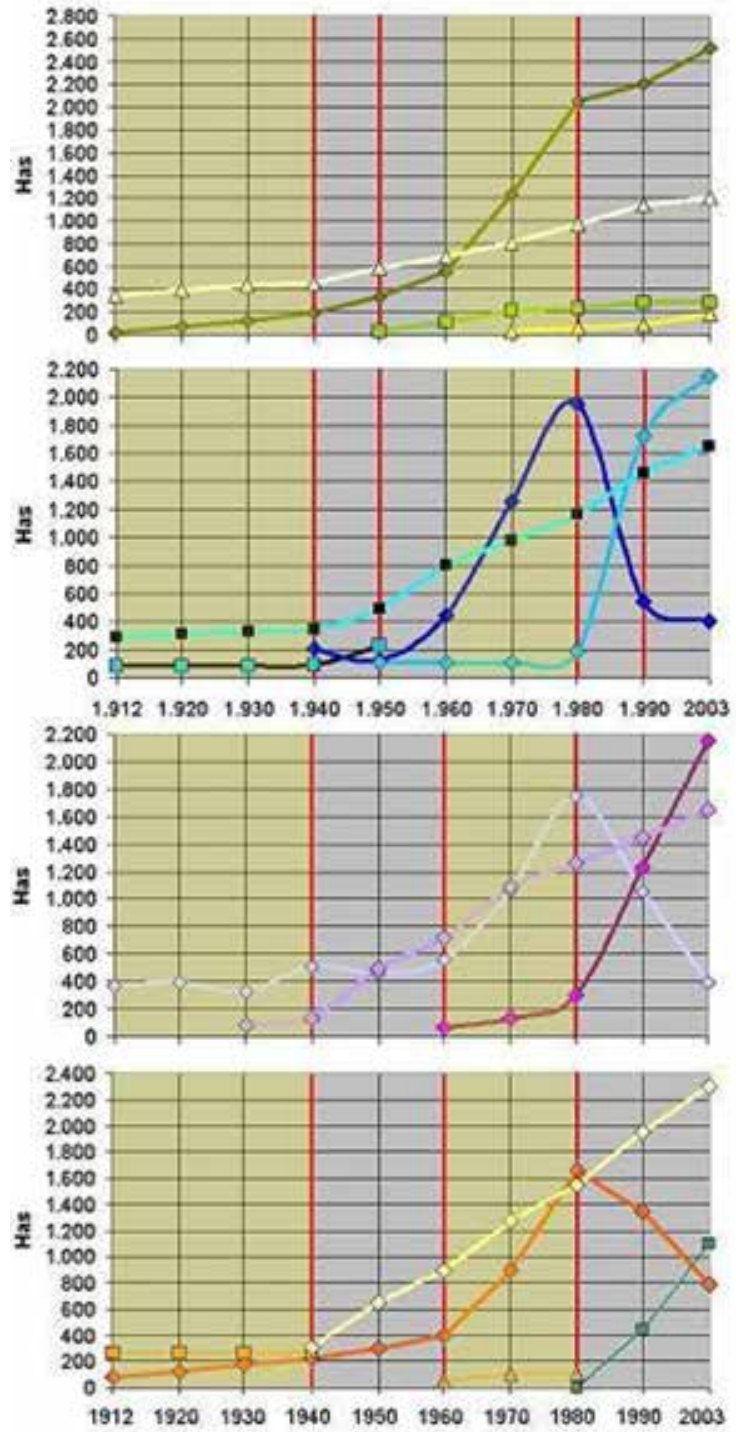

PARCELACIÓN

$\rightarrow$ - llegal en pendiente

- llegal en llano

$\triangle-$ Legal de baja densidad

$\Delta \quad$ Legal de alta densidad

EDIFICACIÓN

$\rightarrow$ Autoconstrucción No Estandarizada

- Autoconstrucción Total Estandarizada

$\triangle$ Autoconstrucción Parcial Estandarizada

$\triangle$ Sin Autoconstrucción y Estandarizada

ABASTECIMIENTO DE AGUA

$\rightarrow$ Fuentes naturales

Sistemas autónomos y/o conexión ileqal

$\leadsto$ Coexistencia de conexión legal e ilegal a la red oficial

- Conexión legal a la red oficial

SANEAMIENTO

$\leadsto$ Sistemas Autónomos

$\approx$ Coexistencia de conexión legal a la red y sistemas autónomos

$\rightarrow$ Conexión legal a la red oficial

PAVIMENTACIÓN

$\rightarrow$ En tierra

- Empedrado

$\triangle$ - Macadam

$\rightarrow$ - Concreto

$\diamond$ Asfalto 

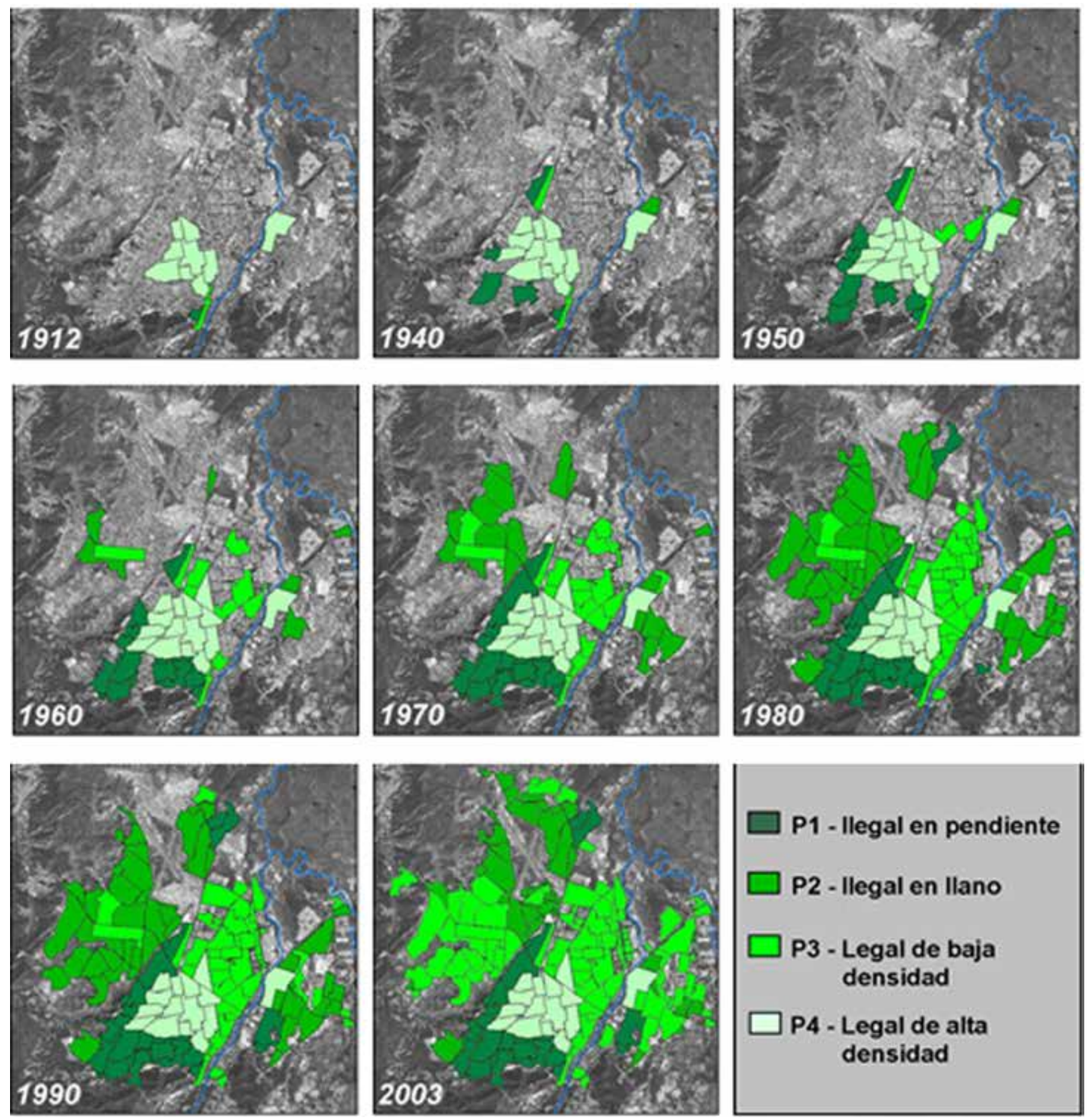

Figura 20. Evolución de la condición de la parcelización en los distintos barrios de la ciudad de Cúcuta. Fuente: Elaboración propia.

los otros servicios en red durante la década 1980-1990. Mientras que el saneamiento y la pavimentación realizaron esta transformación de forma más lenta en el periodo 1980-2003. Cabe destacar en este proceso que la legalización de las parcelas ilegales se realizó una vez legalizada la red de abastecimiento de agua a partir de 1990 y en el periodo 19902003 (ver figura 19).

Si analizamos la figura 20 que nos muestra la evolución espacial de la transformación de las tipologías de parcelación observamos que el cambio más significativo de ilegal en llano (P2) a legal de baja densidad (P3) se produjo principalmente entre 1990 y 2003 en los alrededores de Atalaya

Podemos establecer las siguientes etapas evolutivas de la parcelación: 

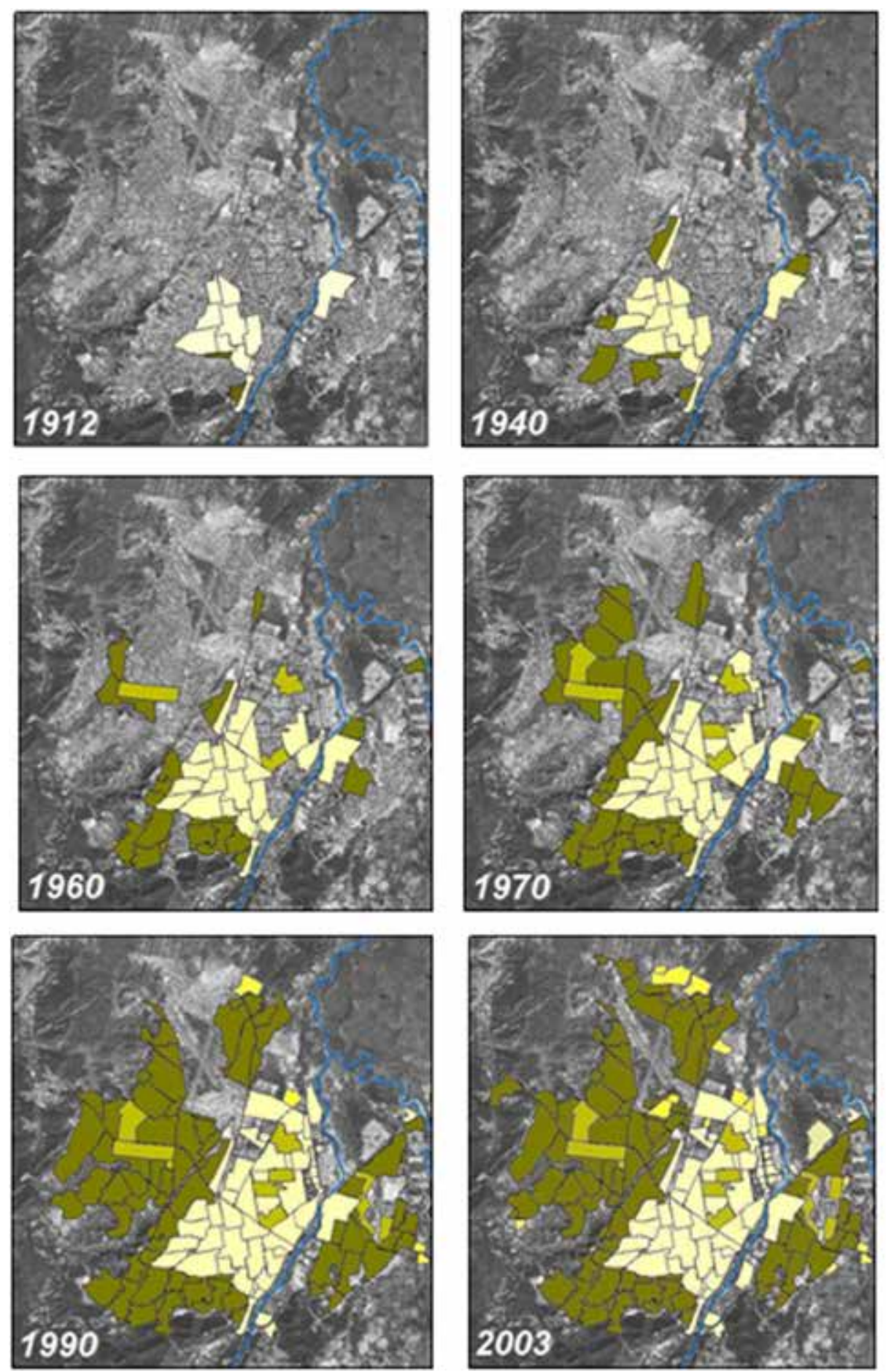

- 1912-1940. Mayor participación de la Parcelación legal de alta densidad del centro urbano [P4].

- 1940-1960. Mayor crecimiento de la Parcelación ilegal en pendiente [P1].

- 1960-1980. Mayor crecimiento de la tipología Ilegal en llano [P2].

- 1980-2003. Mayor crecimiento de Legal de baja densidad [P3].

- 1990-2003. Sustitución de la parcelación Ilegal en Llano [P2] por la Parcelación Legal de baja densidad [P3].

Por su parte, el análisis del componente edificación de vivienda [E] no ha podido ser asociado a su condición de legalidad dependiendo de la misma condición en el origen del barrio. Lo anterior se debe al bajo nivel de registros de reconocimiento de edificaciones realizados
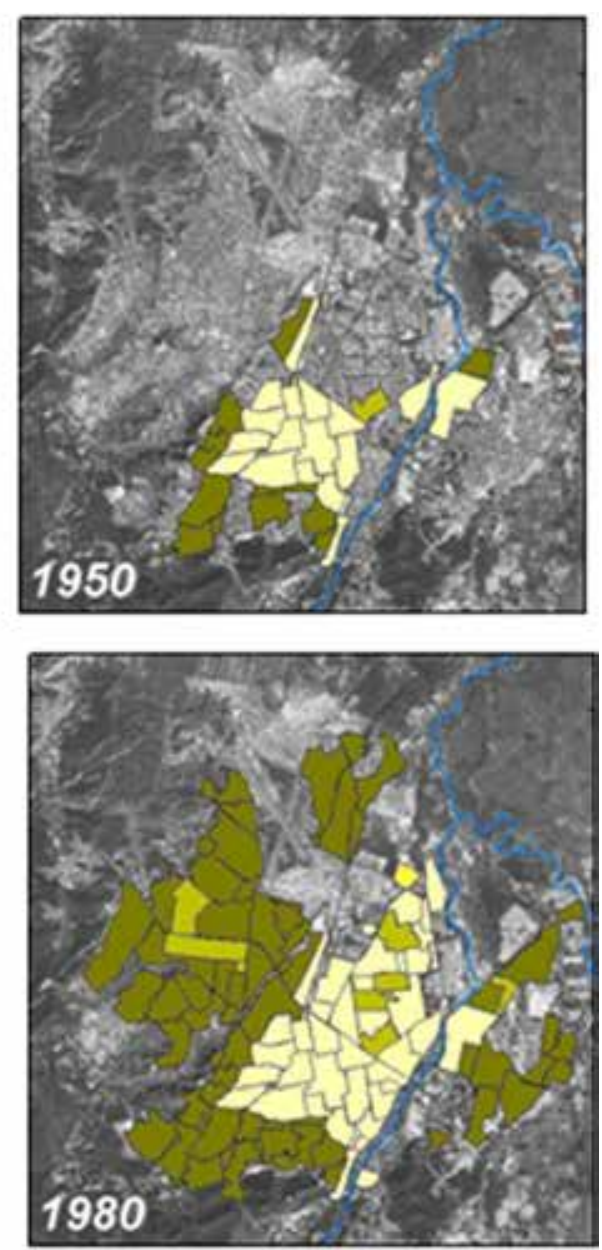

\section{E1 - Vivienda \\ Autoconstruida No Estandarizada}

\section{E2 - Vivienda por Autoconstrucción Total Estandarizada \\ E3 - Vivienda por Autoconstrucción Parcial Estandarizada \\ E4 - Vivienda Sin Autoconstrucción y Estandarizada}

Figura 21 . Evolución de las superficies de expansión de la edificación según tipologías. Fuente: Elaboración propia. 
en los barrios de origen informal. Esta situación no permite plantear el paso de ilegalidad a legalidad en la edificación, tal como se plantea en el componente parcelación por medio de la legalización de barrios. Por lo expuesto, no se ha podido profundizar suficientemente en la componente edificación, que deberá ser estudiada en investigaciones posteriores.

\section{Análisis de los efectos de la introducción de mejoras en los servicios urbanos en la configuración de las formas de crecimiento urbano evolutivas}

Tras combinar en cada sector de la ciudad la condición evolutiva de las redes de servicios y de la parcelación, se plantea la existencia de cuatro tipos de desarrollo en torno a la formalización parcelar:

El tejido Formal, en el cual la legalización predial es inherente al desarrollo del sector desde su inicio. El tejido En Formalización en el que las condiciones de proximidad a los núcleos periféricos y la incorporación de las redes de servicios permiten una pronta formalización. El tejido Potencialmente Formalizable, en el que una mayor lejanía a los núcleos de expansión periféricos y la topografía en pendiente retardan el inicio de la legalización predial. Finalmente, está el tejido Informal en el que las condiciones de una complicada topografía en pendiente, que inciden en la dificultad para la extensión de las redes de servicios, vislumbran poca probabilidad de una legalización parcelar a futuro.

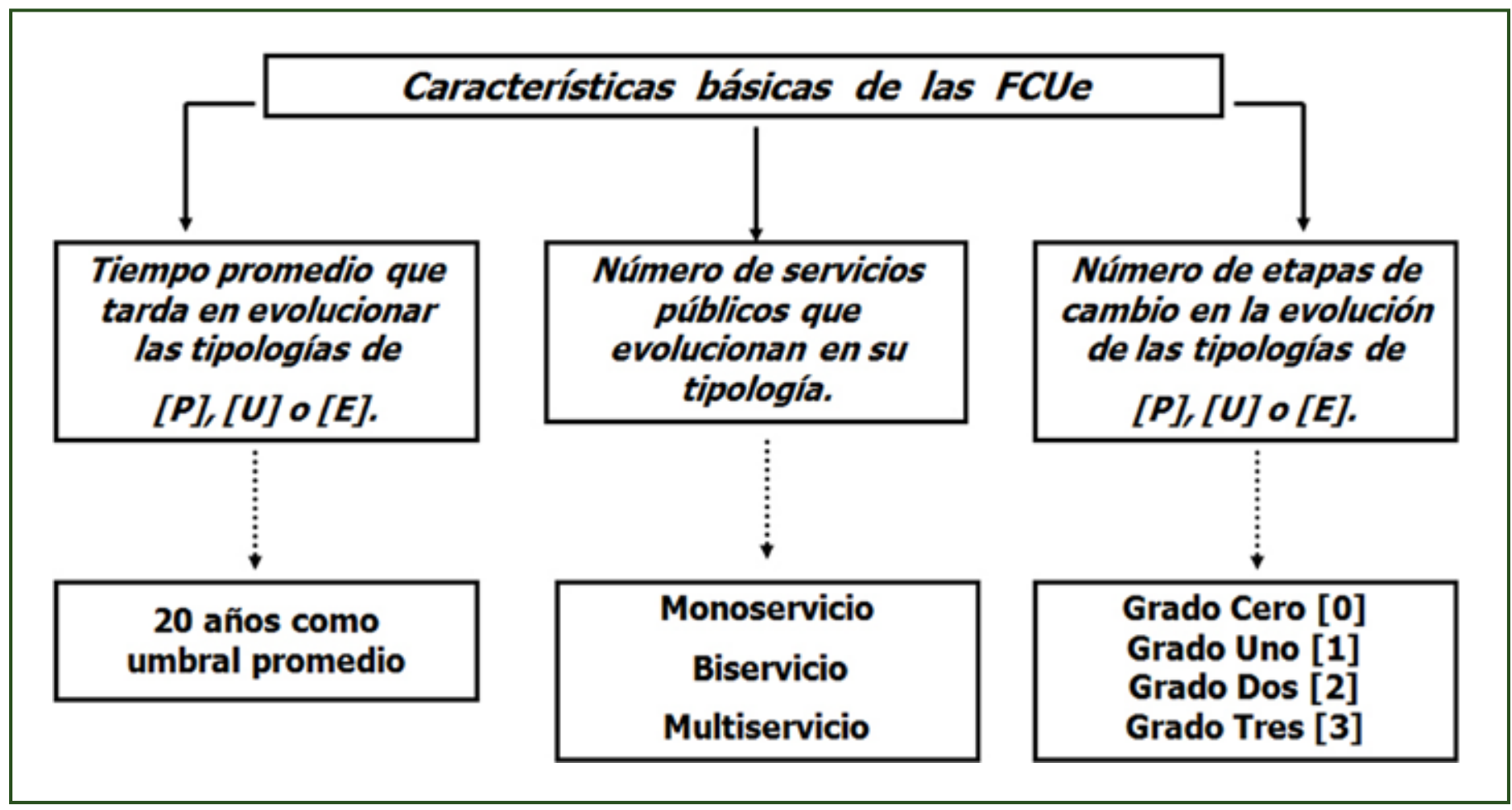

Figura 22. Caracterización de las Formas de Crecimiento Urbano evolutivas según la evolución de los servicios urbanos y su ritmo temporal. Fuente: Elaboración propia.
El planteamiento anterior ha permitido concluir que el tejido informal está ubicado en las zonas de más alta pendiente (ver figura 5). Por su parte, el tejido en formalización se extiende alrededor de los núcleos periféricos y en condición topográfica en llano, contando hoy en día con las redes de servicios públicos oficiales. El tejido potencialmente formalizable también se encuentra ubicado en terreno llano, pero 


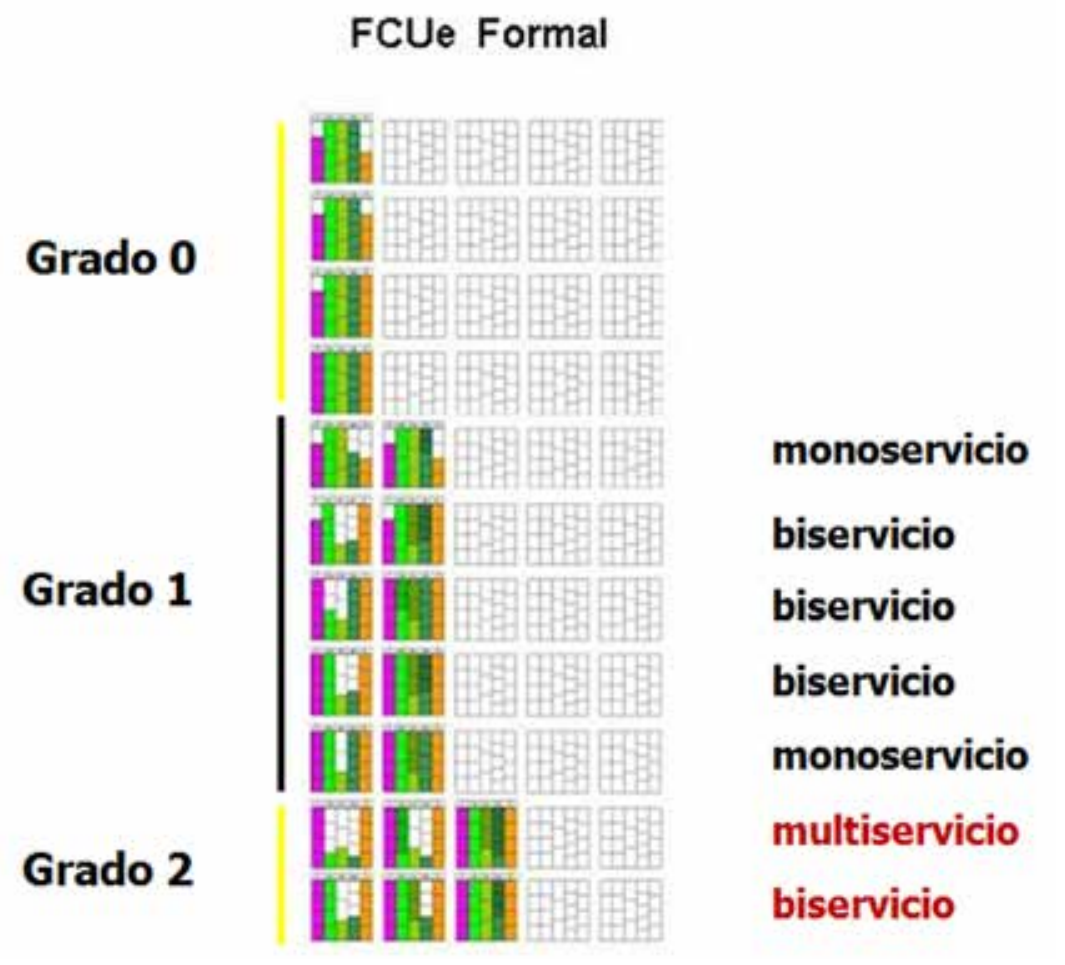

más alejado de los núcleos periféricos que el tejido en formalización. Finalmente, el tejido formal se extiende inicialmente a partir del centro histórico de la ciudad en zonas llanas y se ubica en las denominadas ciudadelas y en la periferia de la ciudad como proyectos de vivienda social. A continuación analizaremos las FCUe según las evoluciones de P, U, E, los servicios que evolucionan y los grados de transformación (ver figura 22).

De este análisis se constatan las siguientes correlaciones (ver figura 23 y figura 24) según los grados o veces que el tejido se transforma por mejoras de P, U o E:

- Las FCU Formal tienen predominio de sectores sin evolución (grado 0). En los sectores evolutivos, las FCU Formal tienen tendencia a desarrollos biservicio de grado 2.

- Las FCU En Formalización tienen tendencia a desarrollos multiservicio de grado 2, con excepción de algunos barrios periféricos que se presentan como biservicio. El número de grados de evolución tiende a disminuir con la distancia a los núcleos periféricos.

- En las $F C U_{e}$ Potencialmente formalizables en llano con evolución, la tendencia es a desarrollos multiservicio. En las FCU Potencialmente formalizables en pendiente la tendencia es a desarrollos biservicio. El número de grados de evolución tiende a disminuir con la distancia a los núcleos periféricos.

- En las FCU Informal, la tendencia es a desarrollos sin evolución o como máximo biservicio.

La figura 24 nos ha permitido establecer la localización geográfica y temporal de las transformaciones urbanas por mejoras de servicios en el que se combina el grado de periferia espacial y su evolución temporal.
FCUe Potencialmente

Formalizable

1

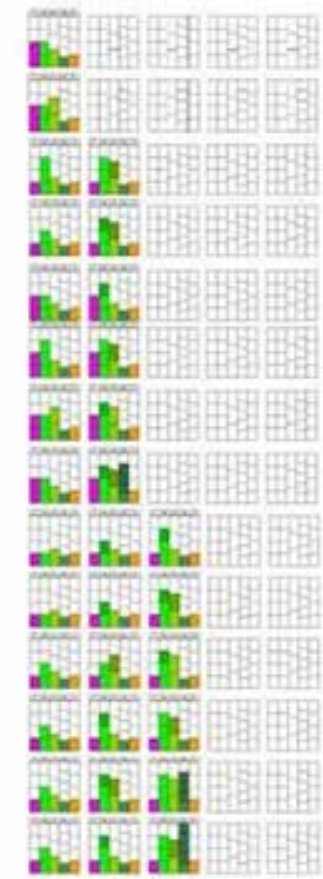

monoservicio

biservicio

monoservicio

monoservicio

monoservicio

multiservicio

monoservicio

biservicio

biservicio

biservicio

multiservicio

multiservicio

Figura 23. Caracterización de las tipologías de las Formas de Crecimiento Urbano evolutivas en el caso de las FCUe Formales y Potencialmente Formalizables en el caso de Cúcuta (Colombia). Fuente: Elaboración propia. 


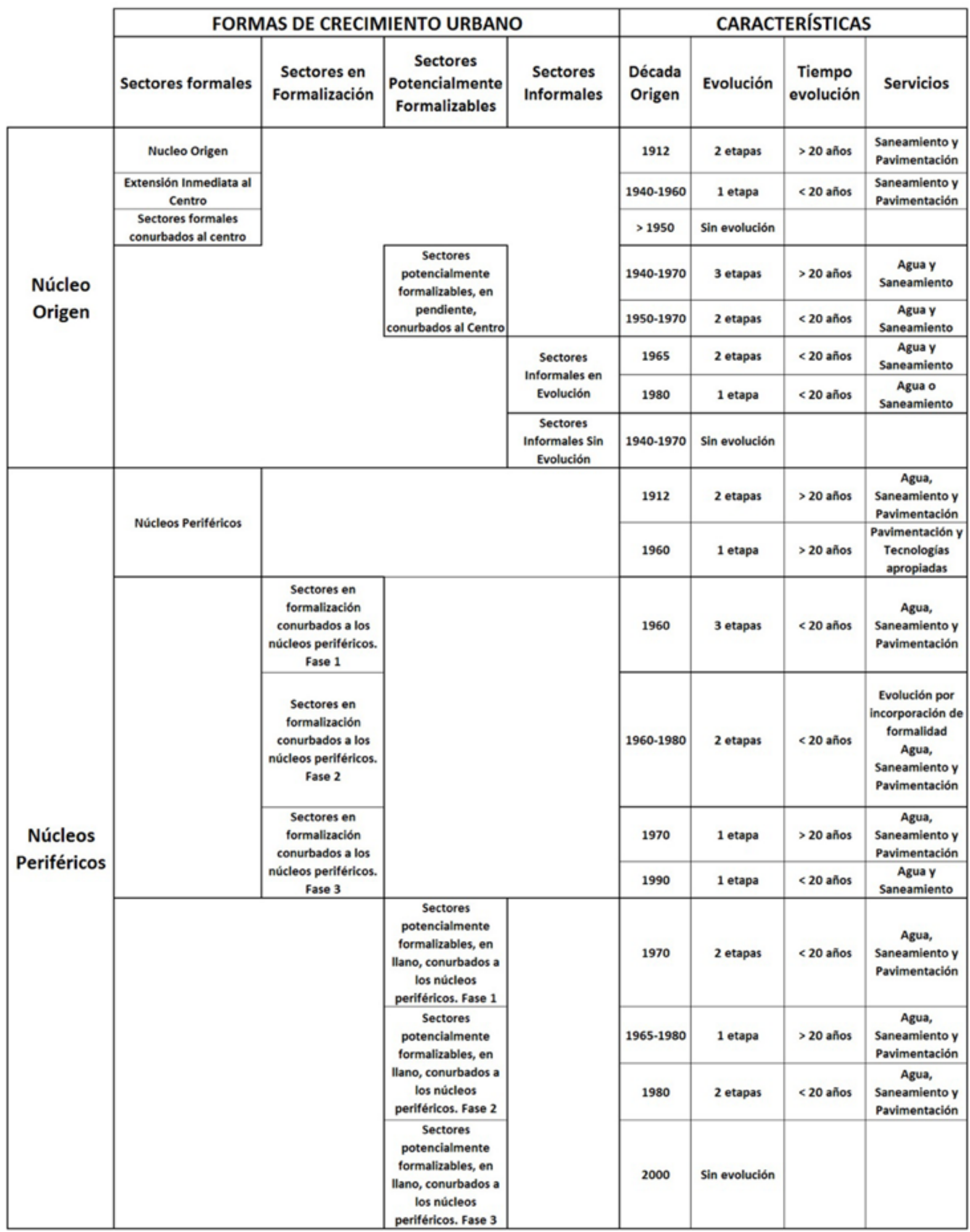

Figura 24. Aplicación de las tipologías de las Formas de Crecimiento Urbano evolutivas al caso de Cúcuta (Colombia). Fuente: Elaboración propia. 


\section{El establecimiento de un índice urbano de} periferia como instrumento de medida del grado de consolidación de los tejidos urbanos

Los análisis anteriores de las formas de crecimiento urbano evolutivas nos permiten desgranar lo que vamos a denominar grados urbanos de periferia. Más allá de una definición de distancia al centro se ha generado un índice de urbano de periferia que es el resultado de la combinación del grado de formalización de los sectores urbanos, de la distancia al núcleo central, de la distancia a núcleos periféricos formales, de la pendiente y del nivel de formalización de servicios urbanos. Este índice nos permitirá posteriormente establecer una correlación con los estratos económicos y el valor del suelo.

La distribución en tiempo y espacio de las tipologías de tejidos urbanos ha permitido establecer la existencia de 11 grados urbanos de periferia, siendo el grado 1 el más central y el grado 11 el de mayor grado de periferia (Figuras 25 y 26 ).

Figura 25. Establecimiento de la jerarquía de criterios para la definición de grados de periurbanización. Fuente: Elaboración propia.

\section{CRITERIOS QUE DEFINEN EL ÍNDICE DE PERIFERIA}

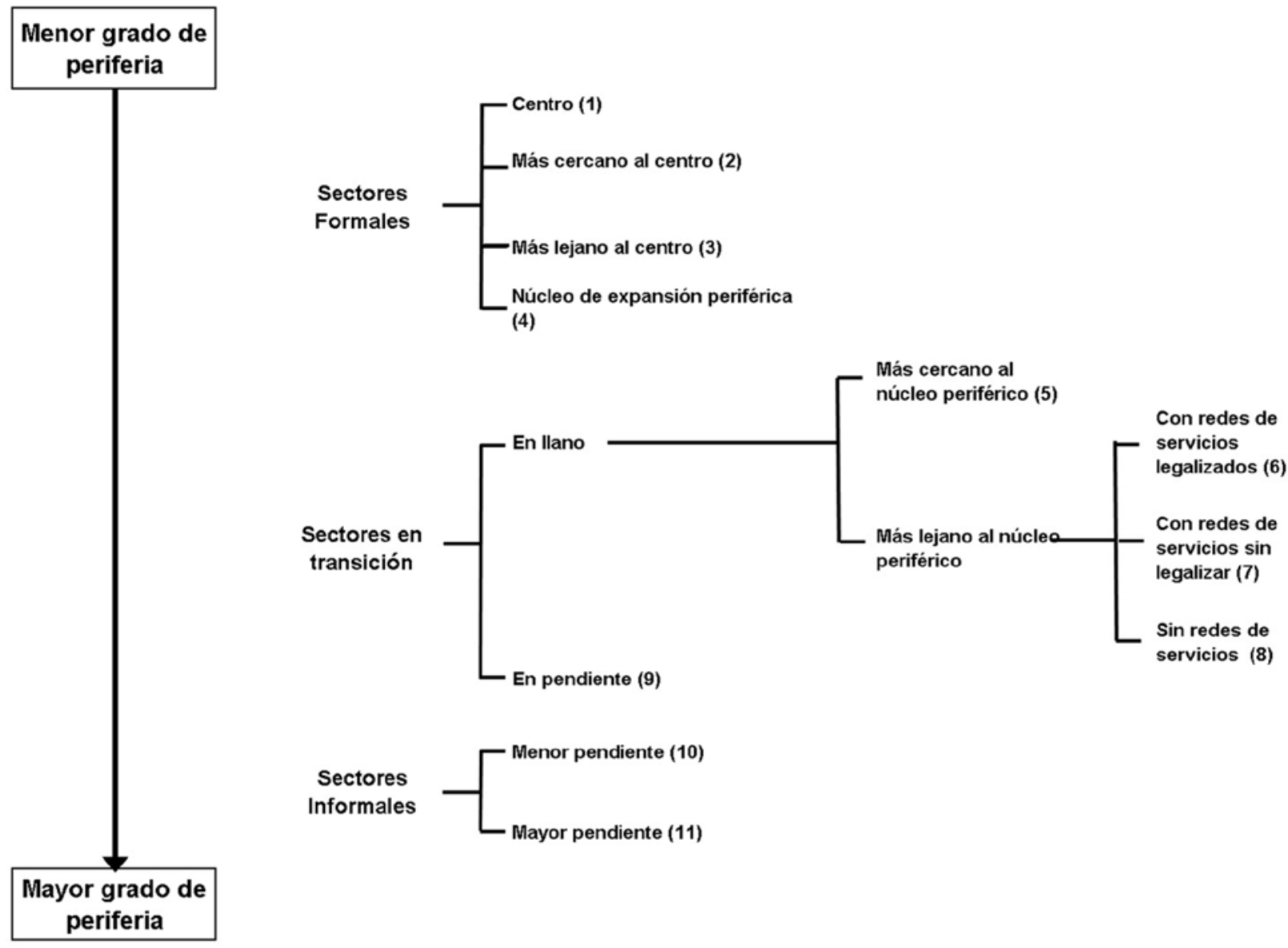

El primer criterio para definir los grados urbanos de periferia de las grandes agrupaciones de las formas de crecimiento urbano evolutivas ha sido el criterio de si el sector es de origen formal (4 primeros grados), si es un sector en transición ${ }^{5}$ (grados del 5 al 9) o si es un sector informal (grados 10 y 11 ).

En la agrupación de los sectores formales ( 4 primeros grados) el criterio

5 Tejidos en formalización y potencialmente formalizables. 
Figura 26. Índice urbano de periferia y su correlación con las Formas de Crecimiento Urbano evolutiva en Cúcuta (Colombia) en 2003. Fuente: Elaboración propia. de clasificación es la distancia o dependencia del Centro, donde a mayor distancia se tiene un mayor grado de periferia. El grado 1 está ligado al núcleo origen de la ciudad, el grado 2 a la extensión inmediata del Centro, el grado 3 a los sectores formales conurbados al Centro y el grado 4 a los núcleos periféricos de iniciativa pública de nueva creación.

Para los sectores en transición, el primer criterio diferencial ha sido la topografía del terreno según sea llano o en pendiente. Para los terrenos en llano se han distinguido aquellos sectores más cercanos a los núcleos periféricos de los que están más lejanos o en la línea de periferia urbana. Los sectores más cercanos se han establecido como grado 5. Para los sectores ubicados en terreno llano y ubicados más lejos del núcleo periférico se han distinguido tres situaciones: la primera es si el sector cuenta con redes de servicios y se halla en proceso de legalización parcelar (grado 6). Un segundo caso es si cuenta con redes de servicios, pero no hay legalización parcelar (grado 7). Finalmente, se encuentran los sectores que se hallan en terrenos en pendiente (grado 8). Con mayor grado urbano de periferia (grado 9) se sitúan los sectores que no cuentan con redes de servicios por la falta de tiempo para su incursión en asentamientos de muy reciente formación.

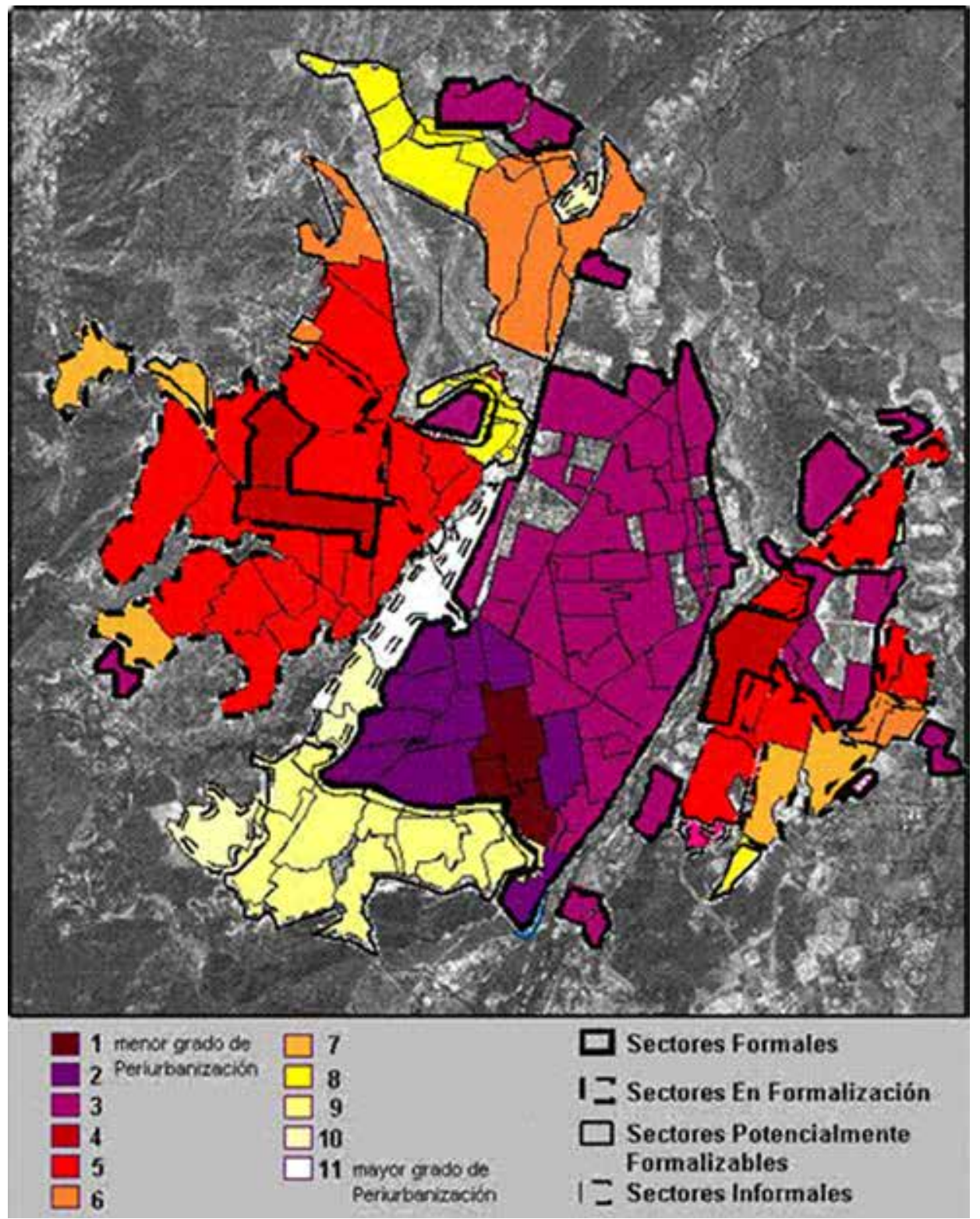

Para los sectores informales el factor discriminante es si hay una mayor o menor pendiente. Los sectores con menor pendiente, es donde se logran incorporar redes de servicio de agua (grado 10). Finalmente, se encuentran los sectores con mayor pendiente, los cuales no han logrado acceder las redes de servicios y son los que tienen un mayor grado urbano de periferia (grado 11). El esquema global se encuentra representado en la figura 25.

El planteamiento de los grados urbanos de periferia va más allá del criterio de los 4 tipos de tejido: formal, en formalización, potencialmente formalizable e informal, sino que se combina el criterio de los tejidos con la distancia a los núcleos periféricos, la cercanía al centro de la ciudad y la disponibilidad de redes de servicios públicos oficiales. Esta cuantificación permitirá establecer correlaciones entre grado urbano de periferia y estratificación socioeconómica y de valor del suelo. 


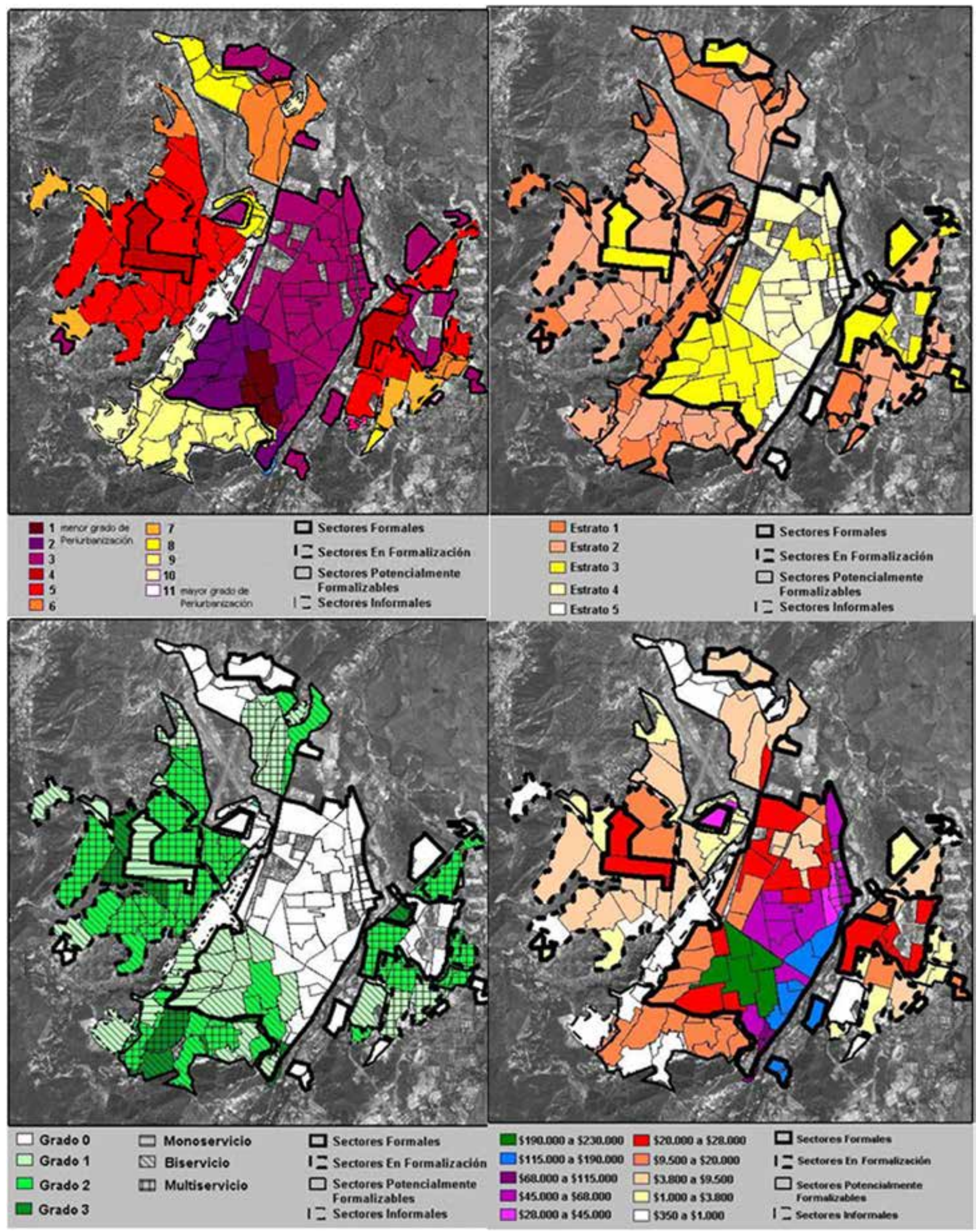

Figura 27. Comparativa entre los Niveles de Estratos Sociales, Valores del Suelo e Índice urbano de periferia según Formas de Crecimiento Urbanos evolutivas. Fuente: Elaboración propia. 
Figura 28. Correlación entre el logaritmo del Valor Comercial del Suelo y el Índice Urbano de Periferia. Fuente: Elaboración propia.

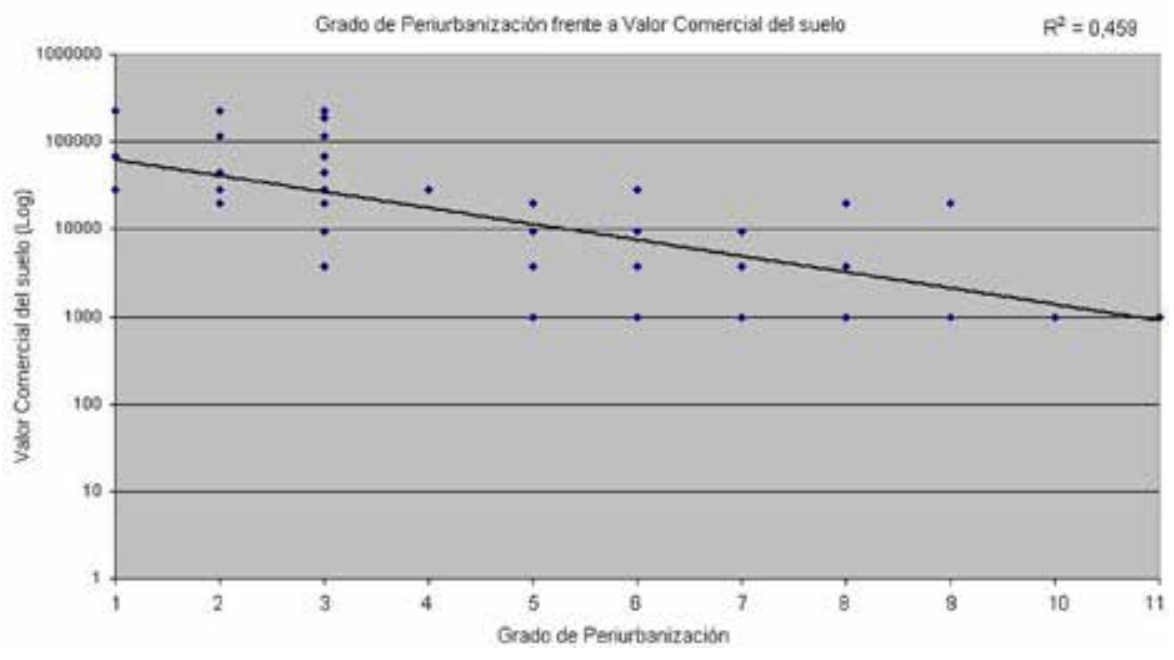

12. Estratificación socioeconómica, valor comercial del suelo y formas de crecimiento urbano correlacionadas con el nivel de periurbanización

De alguna forma, el nivel urbano de periferia, definido a través de las formas de crecimiento urbano y de las características que los configuran, nos definen unos niveles de consolidación establecidos a través del índice urbano de periferia. Se trata ahora de analizar si existen correlaciones entre los niveles urbanos de periferia y la estratificación socioeconómica (estratos sociales), el valor del suelo y los niveles de los servicios urbanos.

De un análisis de la correlación entre Estratificación Socioeconómica y FCUe (ver figura 27) se ha establecido que los sectores con FCU Formal delimitan claramente los sectores en los que se encuentran presentes los estratos 3, 4 y 5 . Los sectores con $\mathrm{FCU}_{\mathrm{e}}$ En Formalización quedan caracterizados por una presencia mayoritaria del estrato 2. Los sectores con FCU Potencialmente formalizables se mueven entre los estratos 1 y 2 dependiendo de si son más o menos periféricos y de si están en pendiente o no. Finalmente, los sectores con FCU Informal presentan estrato 1. Existe, pues, una caracterización clara de los estratos sociales a través de las formas de crecimiento urbano y estratos sociales.

$\mathrm{Si}$ ahora analizamos los sectores con $\mathrm{FCU}_{\mathrm{e}}$ y su correlación con los valores comerciales del suelo constatamos que la FCU Formal presenta los valores más altos (\$230000 a \$28000). Los más bajos de este sector $(<\$ 28000)$ se presentan en proyectos de vivienda social y en las cercanías al Centro que son anteriores a 1950. Por otra parte, se observa que tanto los sectores con FCU en Formalización como los sectores con FCU $_{\mathrm{e}}$ Potencialmente formalizables presentan valores que se mueven entre $\$ 20000$ y $\$ 9500$. Estos se presentan junto al núcleo periférico y los más bajos $(<\$ 1000)$ en la línea de periferia. Finalmente, los sectores con $\mathrm{FCU}_{\mathrm{e}}$ Informal presentan valores en el menor rango $(<\$ 1000)$. Existe, pues, una correlación clara entre FCUe y valores comerciales del suelo. De hecho, se ha observado que el logaritmo del valor comercial del suelo presenta una relación lineal con los grados urbanos de periferia, donde a mayor valor comercial es menor el índice urbano de periferia (ver figura 28).

Finalmente, es de señalar que en los sectores con FCU en Formalización y Potencialmente formalizables existe una correspondencia directa entre el número de servicios mejorados y el valor comercial del suelo. 


\section{Conclusiones}

El estudio de la evolución histórica de la extensión y crecimiento de una población a lo largo de un siglo ha permitido mostrar el interés de un análisis evolutivo de las formas de crecimiento urbano y del rol que en este proceso tienen los mecanismos de mejora de la parcelación, de la urbanización y de la edificación.

Este análisis nos ha permitido mostrar el interés de establecer la agrupación de las formas de crecimiento urbano en estos cuatro grupos:

- Formal. Identifica a sectores que desde su origen han contado con una condición estandarizada para la parcelación, edificación y redes de servicios.

- En Formalización. Corresponde a aquellos sectores de origen informal que al momento de ser evaluados ya contaban con condiciones estandarizadas de parcelación y redes de servicios.

- Potencialmente Formalizable. Cataloga a sectores de origen informal que si bien al momento de ser evaluados no presentaban características estandarizadas de parcelación, sí poseen condiciones que los hacen candidatos a ser catalogados como FCU [En Formalización].

- Informal. Describe a sectores que cuentan con características (orográficas) que difícilmente les permitirá catalogarse como FCU [Potencialmente Formalizable] en un futuro cercano.

Este estudio nos ha confirmado, a su vez, que el mecanismo de formalización sigue el esquema:

Es decir, a partir de unas condiciones iniciales de Parcelación $\left(\mathrm{P}_{\mathrm{i}}\right)$, Urbanización $\left(\mathrm{U}_{\mathrm{i}}\right)$ y Edificación $\left(\mathrm{E}_{\mathrm{i}}\right)$, se produce un mecanismo de mejora de la urbanización $\mathrm{U}_{\mathrm{i}}$ a $\mathrm{U}_{\mathrm{i}+1}$, que a su vez implica una mejora de la edificación, implicando finalmente una mejora en la parcelación hasta su legalización. Este último paso no es más que la capitalización de la inversión a capital fijo en la urbanización y en la edificación.

A su vez, se ha mostrado que el proceso de legalización se inicia cuando se ha legalizado el servicio de abastecimiento de agua, y que a este servicio le acompañan con un decalage de 10 años el saneamiento y la accesibilidad a través de la mejora de las vías pavimentadas. Por otra parte, se pone en evidencia que la mejora de los servicios en los barrios informales se puede afrontar gracias a inversiones previas de la red primaria. En este caso, el decalage es de 20 años.

El rol de la administración, más que solventar el problema de vivienda y urbanización en su totalidad, es el de llevar a cabo procesos top-down y bottom-up, que generan sinergias y mejoran la urbanización. En este caso, la aportación top-down más significativa es la inversión en la estructura primaria de redes de agua y saneamiento (depósitos, impulsiones, colectores principales). En el caso de la aportación bottom-up, se trata de los programas de mejora de barrios con la aportación de material y legitimidad de las asociaciones vecinales con los programas de pavimentación en hormigón o la legalización del servicio de agua. Solamente, tras estos procesos, es posible llevar a cabo el proceso de legalización de los barrios a través del censo de la parcelación y el cobro de impuestos.

La legalización predial no es un elemento que impulse la superación de los niveles socioeconómicos mínimos, es más bien el signo de un desarrollo que se ha propiciado con la incursión de las redes de servicios. 
A partir del análisis de la evolución de la extensión del área urbana y de las redes de servicios se ha definido la existencia de 3 tipos de tejidos, de acuerdo al momento en que las redes son incorporadas al respectivo sector urbano:

a. Tejidos formales, si el asentamiento cuenta con redes desde su formación,

b. Tejidos en transición, si han incorporado las redes tiempo después de su formación, o si se prevé que lo harán en un corto plazo y

c. Tejidos informales, si se prevé que el sector difícilmente logrará incorporar las redes debido a la complejidad de su topografía.

Tras esta jerarquización se concluye que los principios determinantes en la extensión de la urbanización asociada a las redes de servicios son los siguientes:

a. El factor limitante de las altas pendientes consolidó la formación de sectores con tejidos informales con dificultad para la extensión de las redes.

b. En los casos en que la pendiente no es tan pronunciada, pueden llegar a establecerse redes de servicios de agua y saneamiento, pero se dificulta su extensión, y en especial la pavimentación en los sectores más periféricos donde solo se pavimentan los ejes principales.

c. La ausencia de la red vial pavimentada suele darse en la línea de periferia urbana, hecho que condiciona la incorporación de las 3 redes de servicios con la distancia a los núcleos periféricos.

d. El límite periférico de la conurbación en su conjunto, asociado a la reciente urbanización, deja sin tiempo a la entrada de las redes de servicios.

Finalmente, la comparativa entre el índice urbano de periferia y la distribución espacial de los estratos sociales, los valores comerciales del suelo y los grados de transformación de los servicios urbanos nos han mostrado que existe una gran correlación entre ellos, siendo los límites de las cuatro grandes agrupaciones de formas de crecimiento urbano-evolutivas (formal, formalizable, potencialmente formalizable e informal) los umbrales de cambio y los límites de referencia. En un análisis más detallado se ha observado que existe una relación lineal del grado urbano de periferia con el logaritmo del valor comercial del suelo.

Tras este análisis se plantea para futuras investigaciones desarrollar este modelo en otras ciudades y contextos para ratificar la validez de este modelo, y especialmente, evaluar si los proyectos de mejoras de barrios positivos en sí mismos (Brakarz, Greene y Rojas, 2002; Calderon Cockburn, 2004; Salas, 2005; MacDonald, 2005), se ubican en los sectores más pertinentes para una mejora global del conjunto de la ciudad. 


\section{Referencias Bibliográficas}

Arteaga, I. (2005). De periferia a ciudad consolidada. Estrategias para la transformación de zonas urbanas marginales. Bitácora, 9 (1), pp. 98-111.

Brakarz, J., Greene, M. y Rojas, E. (2002). Ciudades para todos. La experiencia reciente en programas de mejoramiento de barrios. Washington: Banco Interamericano de Desarrollo.

Campos, A., et al. (eds.) (2012). Análisis de la gestión del riesgo de desastres en Colombia. Bogotá: Banco Internacional de Reconstrucción y Fomento/Banco Mundial.

Calderon Cockburn, J. (2004). Políticas de Regularización y Mejoramiento Urbano en América Latina. Biblioteca del Foro Electrónico. Suelo: Acceso, regularización y precariedad urbana en América Latina y el Caribe. Santiago de Chile: División de Desarrollo Sostenible y Asentamientos Humanos-CEPAL.

Costa A. y Hernández, A. (2010). Análisis de la situación actual de la regularización urbana en América Latina: La cuestión de la tenencia segura de los asentamientos informales en tres realidades distintas: Brasil, Colombia y Perú. Revista INVI, 25, 68, pp. 121-152.

Decastro, S., HoyoS, M.C. y Umaña, V. (2012). Legalización de barrios informales Prestación de servicios públicos: ¿una medida constitucional paliativa o un paso hacia la legalización? Revista Mayéutica, 5, 22 p. Recuperado de: http://programasocrates.uniandes. edu.co/mayeutica/mayeuticapp.html.

Dematteis, G. (1998). Suburbanización y periurbanización. Ciudades anglosajonas y ciudades latinas. En Monclús, F. J., La ciudad dispersa. Suburbanización y nuevas periferias. Barcelona: Centre de Cultura Contemporánia de Barcelona.

Durand-Lasserve, A. y Clerc, V. (1996). Regularization and Integration of Irregular Settlements: Lessons from Experience. Urban Management Programme Working Paper series. Kenya: UNDP/UNCHS/World Bank.

Hardoy, J.E. y Satterhwaite, D, (1987). La ciudad legaly la ciudad ilegal. Buenos Aires: Grupo Editor Latinoamericano.

Herce, M. y Miró, J. (2002). El soporte infraestructural. Barcelona: Edicions UPC.

Mac Donald, J. (2004). Pobreza y precariedad del hábitat en ciudades de América Latina y el Caribe. Santiago de Chile: CEPAL.

(2005). La otra agenda urbana. Tareas experiencias y programas para aliviar la pobreza y precariedad en las ciudades de América Latina y el Caribe. Santiago de Chile: CEPAL.

Magrinyà, F. (2005). El acceso a los servicios urbanos y la urbanización en los países del Sur: La necesidad de una perspectiva en el espacio y en el tiempo. Cuadernos Internacionales de tecnología para el desarrollo humano, 3, pp. 6-12.
(2008). Les propostes d'Ildefons Cerdà, 1854 1875: l'expressió urbanística i territorial d'un projecte de modernització". Barcelona Quaderns d'Història, 14.

Magrinyà, F. y Urazan, C.F. (2008). Evolución de la cobertura de redes de agua y saneamiento y su relación con el nivel de desarrollo urbano y económico en América Latina y Caribe. Barcelona: UPC.

Mansilla, P. (2013). Los instrumentos del desorden: Estado y actores subnacionales en la producción de los espacios periurbanos, Persona y Sociedad, XXVII, 2, pp. $41-68$.

Monclús, F. J. (1998). La ciudad dispersa. Suburbanización y nuevas periferias. Barcelona: Centre de Cultura Contemporánia de Barcelona.

ONUHABITAT (2009). Urbanización para el desarrollo humano. Bogotá: ONU\&Habitat.

Pelli, V.S. (2010). La gestión de la producción social del hábitat. Habitat y sociedad, 1, pp. 39-54.

Puebla, G. (2010). Caracterización del periurbano en países centrales y periféricos a través de cuatro autores, Breves Contribuciones del I.E.G., 21, pp. 135-155.

Rodríguez, M.C., et al. (2007). Producción social del hábitat y políticas en el Área Metropolitana de Buenos Aires: historia con desencuentros. Buenos Aires: Instituto de Investigaciones Gino Germani y Universidad de Buenos Aires.

Rodriguez Vignoli, J. (2006). Pobreza y Población: enfoques, conceptos y vínculos con las políticas públicas con especial referencia a la experiencia y situación de América Latina. Santiago de Chile: CEPAL.

Salas, J. (2005). Mejora de barrios precarios en Latinoamérica. Bogotá: Editorial Escala.

Solá-Morales y Rubio, M. (1997). Las formas de crecimiento urbano. Barcelona: Ediciones UPC.

Trivelli, P. (1986). Access to land by the urban por An overview of the Latin American experience. Land Use policy, 3, pp. 101-121.

Urazan Bonells, C.F. (2008). El Rol de los Servicios Públicos Básicos en la Evolución de las Formas de Crecimiento Urbano. Estudio de la ciudad de Cúcuta, Colombia. Barcelona: UPC. Tesis Doctoral.

Valladares, L. y Prates Coelho, M. (2003). La investigación urbana en América Latina. Paris: Organización de las Naciones Unidas para la Educación, la Ciencia y la Cultura-UNESCO. Recuperado el 15 de abril de 2014, de: http://www.unesco.org/most/vallspa.htm.

Vargas, I.; Jiménez M, E.; Grindlay, M., A.; y Torres T. C. (2010). Procesos de mejoramiento barrial participativo en asentamientos informales: Propuestas de integración en la ciudad de Ibagué (Colombia), Revista INVI, 25, 68, pp. 59-96. 
URAZÁN BONELLS, Carlos Felipe, y MAGRINYÀ TORNER, Francesc. El rol de los servicios urbanos en la legalización predial y la generación de calidad urbana y valor del suelo. Aplicación al caso de Gúcuta (Colombia). Hábitat y Sociedad, 2015, n. ${ }^{\circ} 8$, pp. 113-145.

$<$ www.habitatysociedad.us.es>

http://dx.doi.org/10.12795/HabitatySociedad.2015.i8.06 $\bigcirc$ 